\title{
Single / Dual-Band Frequency and Polarization Switching Using Frequency Selective Surfaces for Terahertz Applications
}

Ahmed Mosaad Mabrouk ( $\nabla$ ahmed.mosaad@buc.edu.eg )

Badr University in Cairo https://orcid.org/0000-0001-5598-7349

Ahmed Abd Elmoneam Ibrahim

Minia University Faculty of Engineering

Hesham Fathi Hamed

Minia University Faculty of Engineering

\section{Research Article}

Keywords: FSS, Terahertz Band, Polarization Converter, Metasurface

Posted Date: May 21st, 2021

DOl: https://doi.org/10.21203/rs.3.rs-467406/v1

License: (c) (i) This work is licensed under a Creative Commons Attribution 4.0 International License.

Read Full License 


\author{
Single / Dual-Band Frequency and Polarization Switching Using Frequency \\ Selective Surfaces for Terahertz Applications \\ ${ }^{1 *}$ A.M. Mabrouk, ${ }^{2}$ Ahmed A. Ibrahim, and ${ }^{2,3}$ Hesham F.A. Hamed \\ ${ }^{1}$ Faculty of Engineering and Technology, Badr University in Cairo (BUC), Egypt. \\ ${ }^{2}$ Faculty of Engineering, Minia University, Egypt \\ ${ }^{3}$ Faculty of Engineering, Egyptian Russian University, Cairo, Egypt \\ *ahmed.mosaad@buc.edu.eg
}

\begin{abstract}
This paper presents reconfigurable frequency and polarization FSS-based with photoconductive switches in a single and dual-band operation for antenna applications at the terahertz band. The single band FSS unit-cell element exhibits frequency reconfigurability between $0.62 \mathrm{THz}$ and 0.7 THz. It also converts the LP waves into CP over a frequency band ranging from $0.59 \mathrm{THz}$ to $0.8 \mathrm{THz}$ (30 \% 3-dB BW). The dual-band FSS unit-cell element exhibits frequency reconfigurability between $(0.42 \mathrm{THz}$ and $1.03 \mathrm{THz})$ when the switches are turned $\mathrm{ON}$ and $(0.51 \mathrm{THz}$ and $0.865 \mathrm{THz})$ when the switches are turned OFF. Moreover, it exhibits polarization conversion over two bands from 0.46 THz to $0.56 \mathrm{THz}(20 \% 3-\mathrm{dB}$ B.W) and from $0.82 \mathrm{THz}$ to $0.91 \mathrm{THz}(12 \% 3-\mathrm{dB}$ B.W). The dual-band FSS unit-cell element is arranged in a $7 \times 7$ array and used as a reflector for two dipole antennas (A and B) operating at $0.82 \mathrm{THz}$ and $0.5 \mathrm{THz}$, respectively. The same dual-band FSS-based surface enhances their gain to about $8.4 \mathrm{dBi}$ and converts their polarization from $L P$ to $\mathrm{CP}$ at $0.82 \mathrm{THz}$ and $0.5 \mathrm{THz}$, respectively.
\end{abstract}

Keywords: FSS, Terahertz Band, Polarization Converter, Metasurface.

\title{
I. INTRODUCTION
}

An antenna produces electromagnetic waves of different propagation characteristics, depending on their design. In most cases, the produced waves are linearly polarized, which suits a wide range of applications. However, in some cases, like astronomical research and satellite communication systems, circular polarization is needed to counter certain hurdles, such as the ionosphere's Faraday rotation [1]. Thus, a particular converter is needed to switch to circular polarization. Many linear to circular polarization converters of many different technologies have been studied lately. Polarization conversion includes converters that adopt the practice of combining metamaterials with split-ring resonators (SRR) [2], as well as the practice of using frequency selective surfaces (FSS) [3], some of which utilize multiple layers [4]. SRR is an artificial structure being explored in telecommunication for its effect on magnetic susceptibility.

FSS is a concept that consists of repetitive planar arrangements of metallic elements on a dielectric substrate and utilizes a surface of repeated structures that has seen applications in antennas for its ability to transmit and receive selected electromagnetic fields [5]. FSS can break down a single wave into two elements of almost equal power with a phase difference of $90^{\circ}$. This is because of the inductive and capacitive behaviors found in FSS produced in perpendicular directions and allow for wave decomposition. FSS holds multiple advantages such as showing effects of improved antenna gain, as proven in [6] where the incorporation of an FSS superstrate produced a circularly polarized resonant antenna with a high gain, in addition to more control over antenna beam-width, as studied in [7] where a frequency selective surface was used to control the beam-width of an antenna.The FSS technology is comparatively easy to install but poses a trade-off to make it reconfigurable, were to increase the electromagnetic performance, its complexity increases, and therefore its fabrication procedure's simplicity slightly decreases. Besides, to give the converter reconfigurable features, the number of elements must heavily increase [8]. 
Reconfigurability gives an antenna substantial merit. Multiple studied applications give reconfigurable converter features, such as the addition of PIN diodes [9] [10], liquid crystals [11], varactor diodes [12] [13], or the usage of microelectromechanical systems (MEMS) [14]. Each of which plays a vital role in the benefits and drawbacks mentioned above. The application of FSS has been lately considered for use in the terahertz band, which had been comparatively less explored due to its complexity, lack of needed components, and the easy obstruction of its waves caused by their small size. Even today, terahertz waves have posed a challenge to researchers in intercepting and guiding [15].

Terahertz frequency band currently holds an appealing position in researchers' eyes due to being the potential successor to the fifth generation (5G). It may provide extra features such as the possible decrease in transceiver size and better energy efficiency, as seen in [16], which discusses all the so-far known challenges and standardizations needed for the terahertz band, as well as all its potential applications. By manipulating the layout and shape of the structure of the FSS, it produces an effect on the electromagnetic waves that, in exchange, cause suppression of specific frequencies and passage of other frequencies. Through an intricate design, intercepting terahertz waves may be possible through FSS integrated systems.

This paper presents a reconfigurable linear to circular polarization converter that operates on the terahertz band, contrasting to most converters that operate on gigahertz bands [17]. The converter is based on the FSS layout, which in addition to its previous benefits, also boasts its low-profile structure and relative ease of fabrication. The designed converter is simulated based on CST-MW studio, powerful software for computing devices' effect in a virtual electromagnetic environment. The produced plots will be later displayed, along with an analysis of the obtained results. In the following sections, the basic design of the converter and the methods used will be discussed. The chronological steps used to attain the final results are also included to highlight different techniques' effects. A discussion of the obtained results and the overall conclusion of the performed research are introduced at the end of this paper.

\section{Frequency RECONFIGURABLE FSS UNIT-CELL ELEMENT}

\section{A. Initial Design}

This paper starts with the design of a primary unit cell of the converter. As the end product is a frequency selective surface composed of repeated small elements, the term "unit cell" is suitable to describe these components that make up the lattice-like surface. The unit cell has a metasurface and uses silicon as a substrate with a dielectric constant $\left(\varepsilon_{\mathrm{r}}\right)$ of 11.9 and a thickness of $\mathrm{h}=60 \mu \mathrm{m}$. It has a side-length of $\mathrm{L}=60 \mu \mathrm{m}$, the width of $\mathrm{W}=79.35 \mu \mathrm{m}$, and three slots each of gap-width $\mathrm{d}=2 \mu \mathrm{m}$ as shown in Fig. 1 . The FSS unit cell's internal design took the shape of a bee-hive-like dual hexagonal structure of a side length of $20 \mu \mathrm{m}$ and placed it at both sides of the substrate.

Six photoconductive switches are then added at the upper and lower slots and vary between ON and OFF states, as shown in Fig .2. Photo-conductive switching elements are manufactured based on semiconductors like gallium-arsenide ( $\mathrm{GaAs}$ ) and silicon $(\mathrm{Si})$ [18]. Using photoconductive switches for reconfigurability eliminates the usage of biasing lines and connecting wires, resulting in higher isolation, lower interference, and significantly higher switching speed than the other switching elements [19]. The photo-conductive switch is used in antennas to achieve the pattern, polarization, and frequency reconfigurability [20]. Here, the photoconductive diodes are used to achieve frequency reconfigurability. 


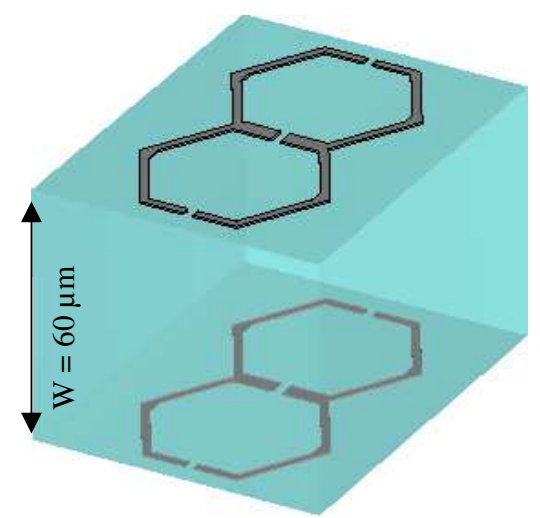

a.

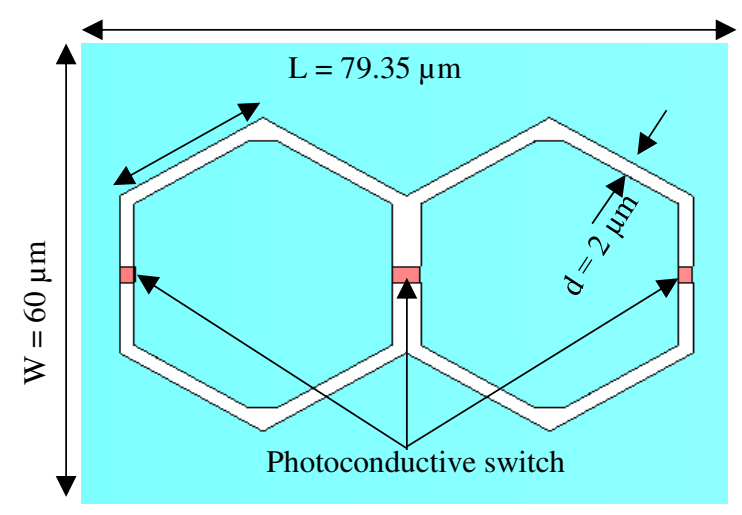

b.

Fig .1 a. The 3D view and b. the top view of the proposed FSS unit cell element's configuration.

This unit-cell element is analyzed using Floquet boundary in CST-MW studio. It was found that when the photoconductive switches are turned $\mathrm{ON}$, the magnitudes of the reflection and transmission coefficients of the proposed FSS unit-cell element have the same value at $-3 \mathrm{~dB}$ (at $0.55 \mathrm{THz}$ ) and a fixed phase difference of $\Delta \varphi=90^{\circ}$ over the operating frequency band from $0.35 \mathrm{THz}$ to $0.69 \mathrm{THz}$ as shown in Fig .2.

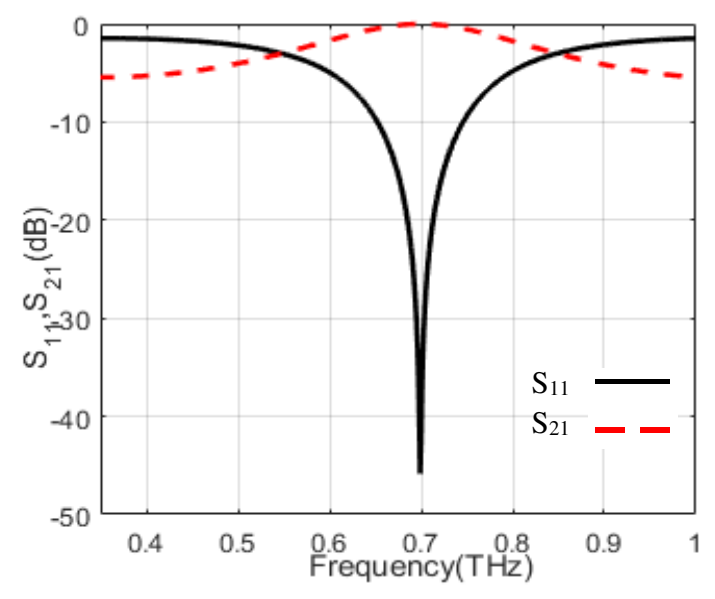

a.

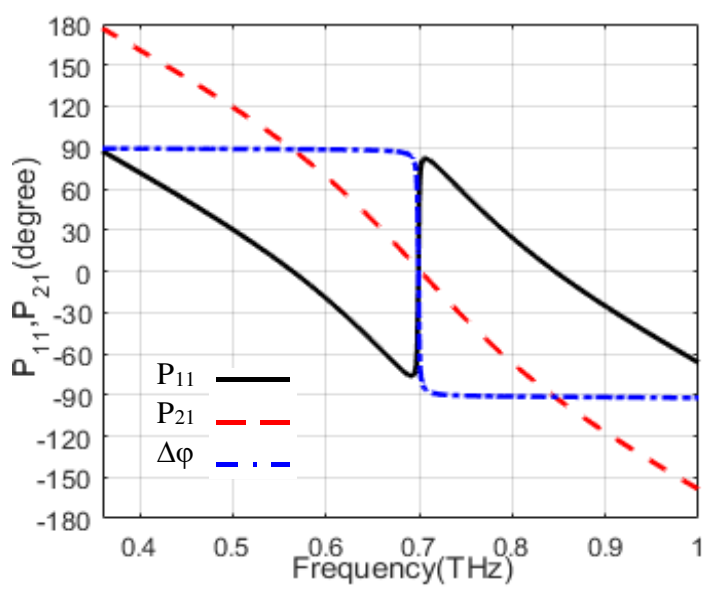

b.

Fig .2 The variation of a. the magnitude and $b$. the phase of the reflection and transmission coefficients of the proposed FSS unit-cell element when the switches are turned ON.

When the switches turned OFF, the minimum value of $S_{11}$ shifted to $0.62 \mathrm{THz}$. The magnitudes of the reflection $\left(S_{11}\right)$ and transmission $\left(S_{21}\right)$ coefficients of the proposed FSS unit-cell element have the same value at $-3 \mathrm{~dB}$ (at $0.5 \mathrm{THz}$ ) and a fixed phase difference of $\Delta \varphi=90^{\circ}$ over the operating frequency band from $0.35 \mathrm{THz}$ to $0.59 \mathrm{THz}$ as shown in Fig .3. 


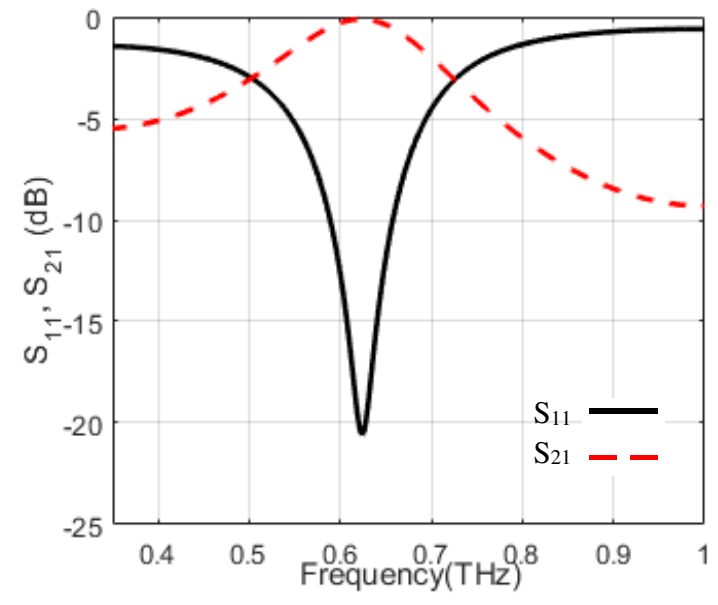

a.

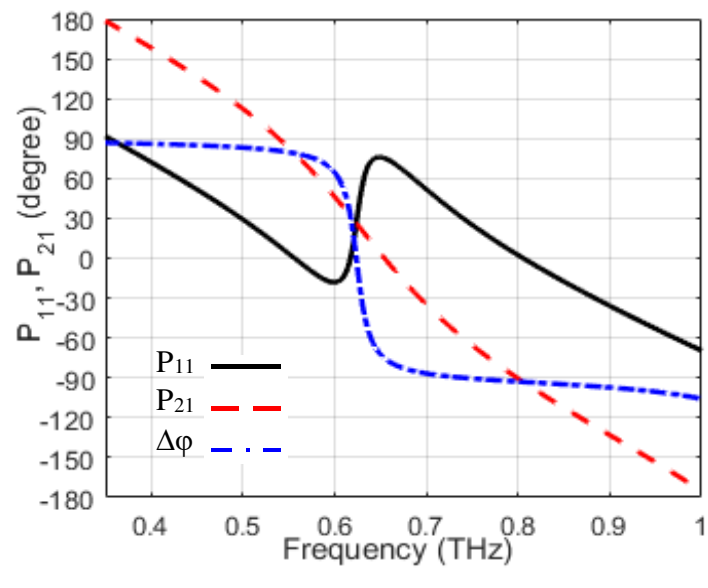

b.

Fig .3 The variation of a. the magnitude and b. the phase of the reflection and transmission coefficients of the proposed FSS unit-cell element when the switches are turned OFF.

This frequency reconfigurable FSS unit-cell element can be arranged in a periodic structure and used for antennas enhancing their gain values, as discussed through this paper.

\section{B. Dual-Band Reconfigurable FSS unit-cell Element}

Based on the previous research study for a stopband filter [21] which implements the use of a Jerusalem cross shape., a cross-like shape is implemented to the initial unit cell design, where a vertical line intersects the hexagon. Each vertical line has its own perpendicularly intersecting horizontal line of $7 \mu \mathrm{m}$ length and said the horizontal line has two $6 \mu \mathrm{m}$ vertical lines at each end, as shown in Fig .4.

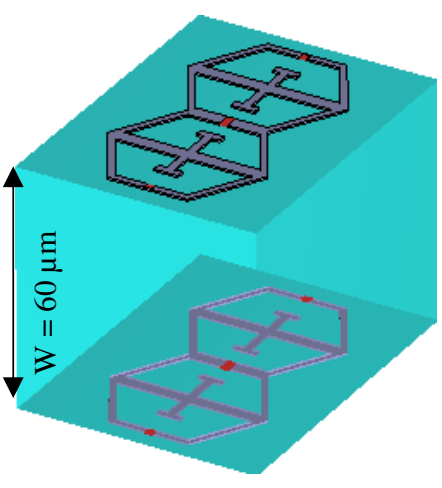

a.

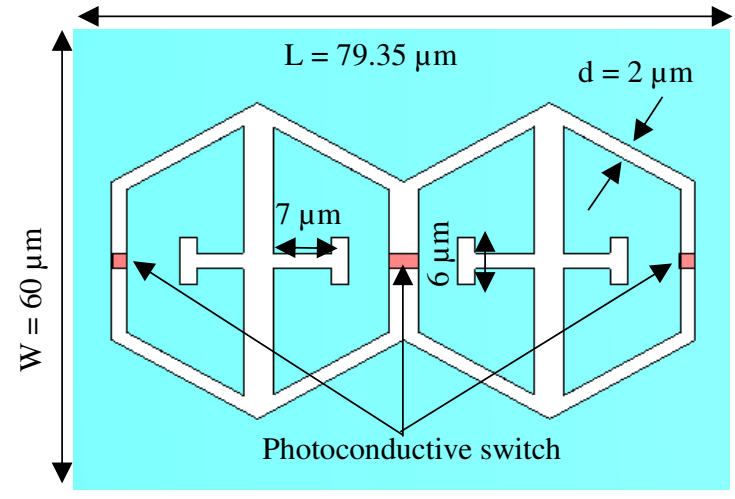

b.

Fig .4 a. The 3D view and b. the top view of the proposed dual-band FSS unit cell element's configuration.

It was found that when the photoconductive switches are turned $\mathrm{ON}$, the magnitudes of the reflection and transmission coefficients of the proposed FSS unit-cell element have the same values at $0.42 \mathrm{THz}$ and 1.03 THz. It also can operate over two frequency bands with center frequencies $0.56 \mathrm{THz}$ and $1.07 \mathrm{THz}$, as 
shown in Fig .5a. The phase difference of $\varphi=90^{\circ}$ is obtained over the dual-bands (from $0.35 \mathrm{THz}$ to 0.58 $\mathrm{THz}$ ) and (from $0.59 \mathrm{THz}$ to $1.0 \mathrm{THz}$ ) as shown in Fig .5b.

When the switches are turned OFF, new frequency bands are obtained with minimum $S_{11}$ values at frequencies of $0.52 \mathrm{THz}$ and $0.84 \mathrm{THz}$, as shown in Fig .6a. Also, the phase difference of $\Delta \varphi=90^{\circ}$ is obtained over the dual-bands (from $0.35 \mathrm{THz}$ to $0.5 \mathrm{THz}$ ) and (from $0.73 \mathrm{THz}$ to $0.85 \mathrm{THz}$ ) as shown in Fig .6b. Switching the photoconductive diodes enables the proposed FSS unit-cell element to operate at four different operating frequencies for terahertz range' applications.

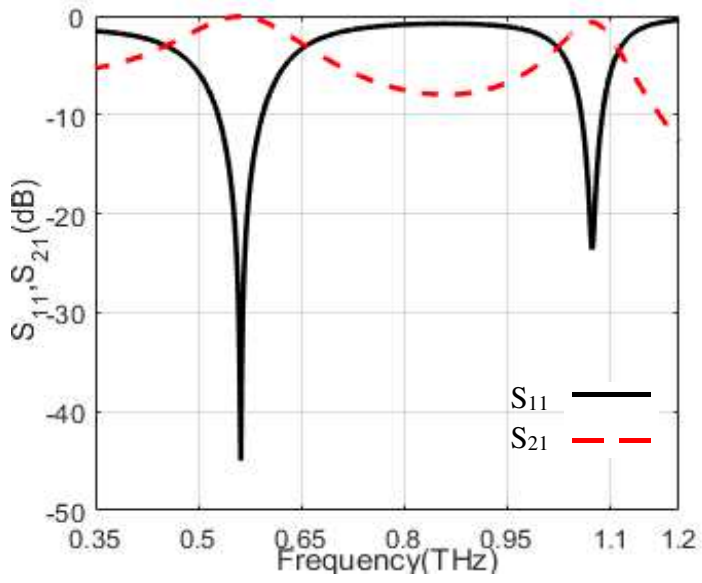

a.

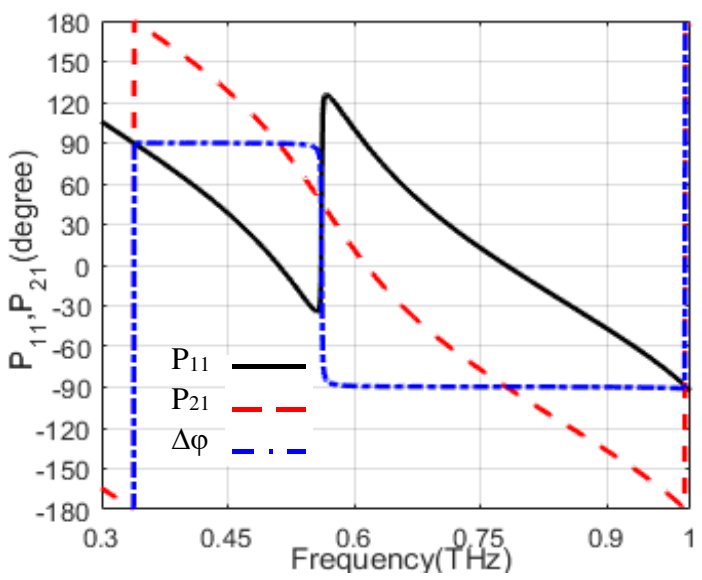

b.

Fig .5 The variation of a. the magnitude and $b$. the phase of the reflection and transmission coefficients of the proposed dual-band FSS unit-cell element when the switches are turned OFF.

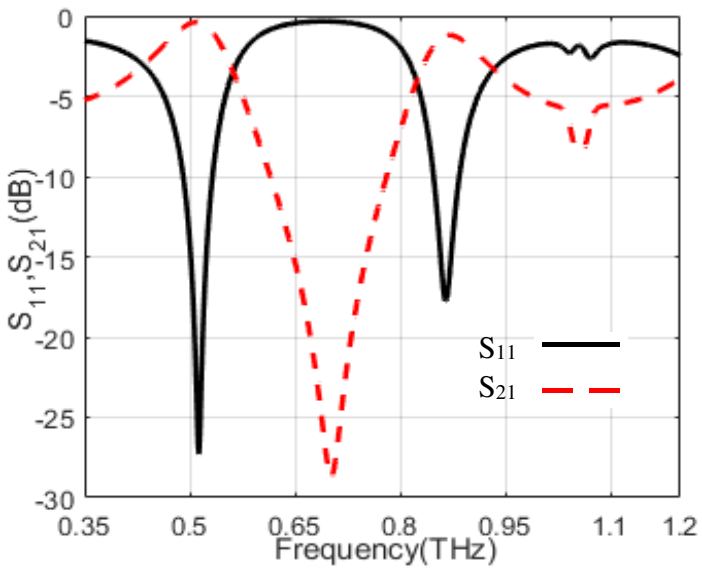

a.

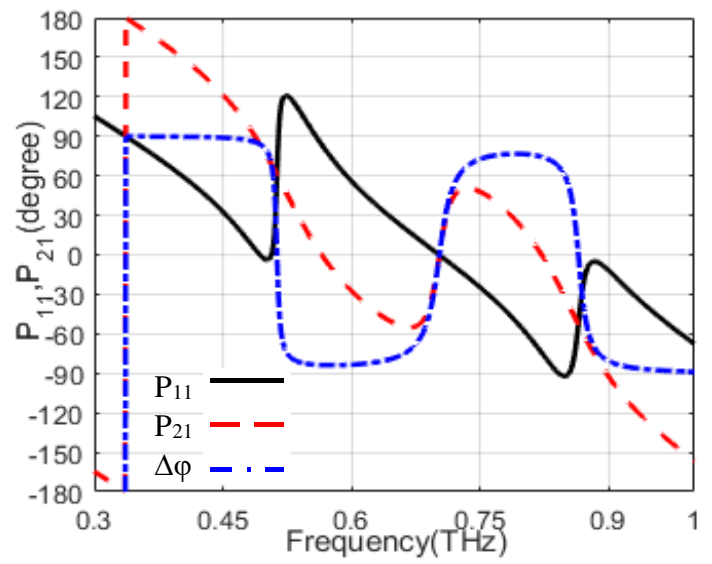

b.

Fig .6 The variation of a. the magnitude and b. the phase of the reflection and transmission coefficients of the proposed dual-band FSS unit-cell element when the switches are turned ON.

\section{III.Polarization Reconfigurable FSS Unit-Cell Elements}

\section{A. Conversion Fundamentals}

In both forms of polarization (linear and circular), the electromagnetic wave travels at a uniform rate. A linearly polarized wave oscillates over a specific axis (propagation direction), while the circularly polarized wave rotates along the axis. For theoretical conversion from linear to circular polarization, a couple of rules need to be taken to account. The transmitting wave is a superposition of two orthogonal elements of the same magnitude. The amplitude can be represented by $\mathrm{E}^{\mathrm{t}}$ can be found in [22]: 


$$
\vec{E}^{t}=\vec{E}_{x}^{t}+\vec{E}_{x}^{t}=E_{0}^{t}\left(T_{x} \hat{x}+T_{y} \hat{y}\right) e^{-j k z}
$$

where $T_{x}$ and $T_{y}$ are reflections and transmission parts of the transmission matrix [T]:

$$
\left[\begin{array}{l}
T_{x} \\
T_{y}
\end{array}\right]=\left[\begin{array}{l}
\left|T_{x}\right| e^{-j \varphi_{x}} \\
\left|T_{y}\right| e^{-j \varphi_{y}}
\end{array}\right]
$$

For the conversion to occur, two conditions must be obtained at the operating frequency, which is stated as follows:

$$
\left|T_{x}\right|=\left|T_{y}\right| \text {, and } \Delta \varphi= \pm 90^{\circ}
$$

where,

$$
\Delta_{\varphi}=\varphi_{x}-\varphi_{y}
$$

The two FSS unit-cell elements in the previous section satisfy the fundamentals of linear to circular polarization conversion. To confirm the unit-cell element's conversion credibility, the axial ratio concerning frequency is constructed. The transmission coefficients of both fields are represented in the equation as $T_{x x}$ and $T_{y y}$, which in Figures 4 and 6 gave an outcome of equal coefficients with a $\pm 90^{\circ}$ phase difference, proving the generation of a correct circularly polarized wave.

$$
\begin{aligned}
& A R=\frac{10 \log _{10}\left(T_{x x} \cos \tau+T_{y y} \cos \Delta \Phi \sin \tau\right)^{2}+T_{y y}^{2} \sin ^{2} \Delta \Phi \sin ^{2} \tau}{\left(T_{x x} \sin \tau+T_{y y} \cos \Delta \Phi \cos \tau\right)^{2}-T_{y y}^{2} \sin ^{2} \Delta \Phi \cos ^{2} \tau} \\
& \tau=1 / 2 \tan ^{-1}\left(\frac{2 T_{x x} \cos \Delta \Phi}{T_{x x}^{2}-T_{y y}^{2}}\right)
\end{aligned}
$$

\section{A. Results and Analysis}

For the single band FSS unit-cell element, the axial ratio is calculated when the photoconductive switches are turned OFF and ON. It was found that the proposed single band FSS unit-cell element shown in Fig .1 has a wide 3-dB axial ratio band from $0.59 \mathrm{THz}$ to $0.8 \mathrm{THz}(30 \% 3-\mathrm{dB} \mathrm{BW})$ if all switches are at OFF state as shown in Fig .7a. This is mean that the unit-cell element suitable for polarization conversion applications at that band of frequencies. However, when all switched turned ON, the proposed FSS unitcell element lost the polarization conversion conditions.

The dual-band FSS unit-cell element shown in Fig .4 had a polarization conversion property when the switches turned OFF. It exhibits dual 3-dB AR bands; the first one ranging from $0.46 \mathrm{THz}$ to $0.56 \mathrm{THz}$ (20\% 3-dB B.W) and the other ranging from $0.82 \mathrm{THz}$ to $0.91 \mathrm{THz}(12 \% 3-\mathrm{dB}$ B.W) as in Fig 7.b. So, the dual-band FSS-based unit-cell element is suitable for polarization conversion of different antennas with operating frequencies within these two bands. 


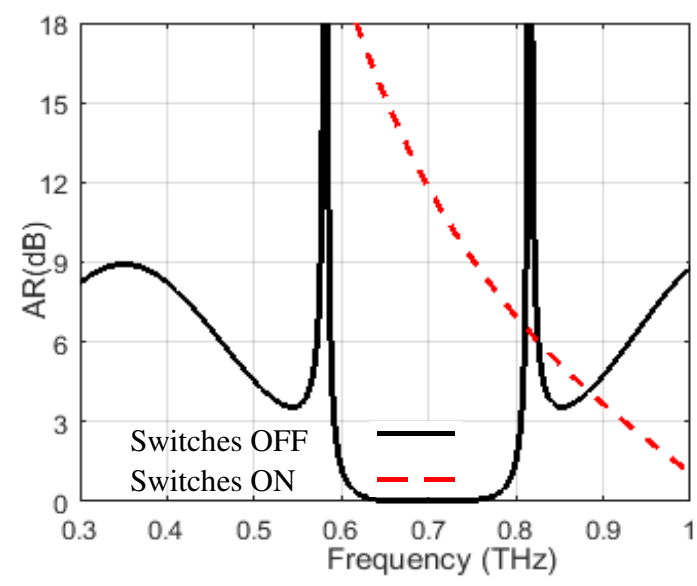

a.

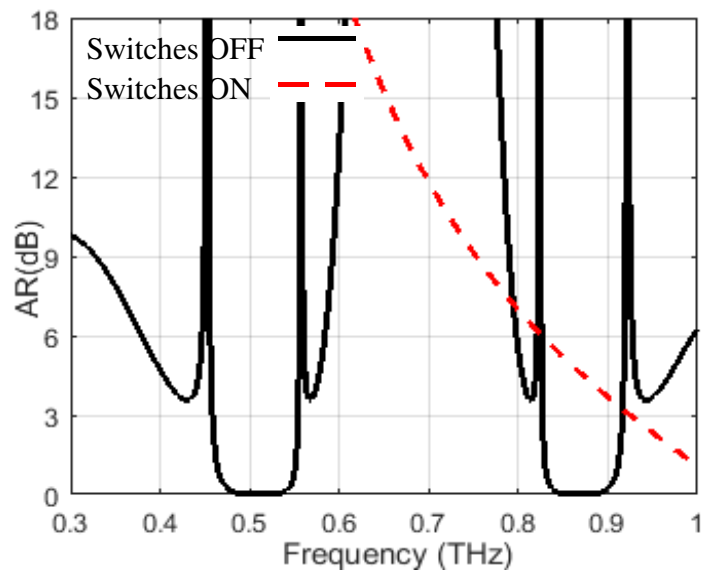

b.

Fig .7 The variation of axial ratio versus frequency for a. the single-band and b. the dual-band FSS unitcell elements when the switches are turned OFF and ON.

As seen in Table 1, which details the proposed converter's features concerning other converters, this converter excels in operating at dual-band resonance, contrasting with the rest of the converters. Its terahertz frequency focus results in having proportionally smaller dimensions. Its meager size would be ideal for implementation in any area or device, as its near-negligible dimensions fit modern size constraints imposed by the advancement of technology and the necessity to take up the least space as possible.

Table 1: A comparison between the proposed converter and other polarization converters

\begin{tabular}{|c|c|c|c|c|c|c|}
\hline Converter & $\begin{array}{c}\text { Used } \\
\text { Technique }\end{array}$ & Unit cell area & $\begin{array}{c}\text { Used } \\
\text { Material }\end{array}$ & $\begin{array}{c}\text { Operating } \\
\text { bands }\end{array}$ & $\begin{array}{c}\text { Configuration } \\
\text { with antenna }\end{array}$ & $\begin{array}{c}\text { Overall } \\
\text { size and } \\
\text { cost }\end{array}$ \\
\hline$[22]$ & Metamaterial & $190 \times 190 \mu \mathrm{m}^{2}$ & Gold & Single-band & N/A & High \\
\hline$[23]$ & Metamaterial & $110 \times 110 \mu \mathrm{m}^{2}$ & Gold & Single-band & N/A & High \\
\hline $\begin{array}{c}\text { Proposed } \\
\text { converter }\end{array}$ & FSS & $79.35 \times 60 \mu \mathrm{m}^{2}$ & Aluminum & Dual-bands & $\begin{array}{c}\text { Introduced } \\
\text { for both bands }\end{array}$ & Low \\
\hline
\end{tabular}

\section{High Gain Reconfigurable Polarization Conversion Dipole Antenna}

\section{A. Proposed Dipole Antenna Design}

Two linear polarized (LP) dipole antennas are designed to resonate at the frequency of $0.82 \mathrm{THz}$ and 0.5 $\mathrm{THz}$ as applications for the dual-bands FSS-based unit-cell elements. These proposed antennas are placed over an $\mathrm{N} x \mathrm{~N}$ FSS array through the next section adding polarization reconfigurability feature to them, enhancing their gain, and enabling polarization reconfigurability.

The first proposed dipole antenna (antenna A) that resonates at $0.82 \mathrm{THz}$ consists of a rectangular perfect electric conductor (PEC) of side length $\mathrm{L}_{\mathrm{d}}=125 \mu \mathrm{m}$ and width $\mathrm{W}_{\mathrm{d}}=12 \mu \mathrm{m}$. The dipole antenna's radiator is placed over a square-shaped substrate of relative permittivity of $\varepsilon_{\mathrm{r}}=3.38$, a side length of $\mathrm{L}_{\mathrm{s}}=200 \mu \mathrm{m}$ and height of $\mathrm{H}_{\mathrm{s}}=10 \mu \mathrm{m}$ as shown in Fig .8a. This antenna operates over a $-10 \mathrm{~dB}$ bandwidth ranging from $0.76 \mathrm{THz}$ to $0.91 \mathrm{THz}(18 \% \mathrm{BW})$, as shown in Fig .8b. The proposed $0.82 \mathrm{THz}$ dipole antenna radiates an LP wave omnidirectionally with a maximum gain value of $2.47 \mathrm{dBi}$, as shown in Fig .9a. The 2D 
components of the radiated left $\left(\mathrm{E}_{\mathrm{L}}\right)$ and right $\left(\mathrm{E}_{\mathrm{R}}\right)$ hand electric field are equal at the operating frequency, as shown in Fig .9b.

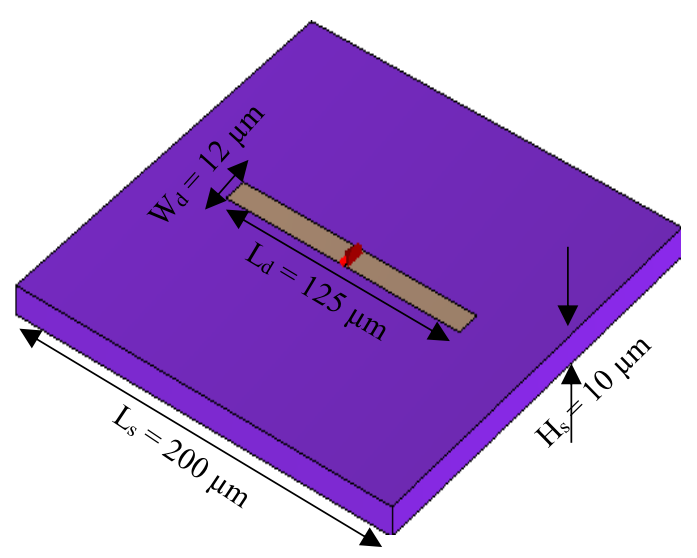

a.

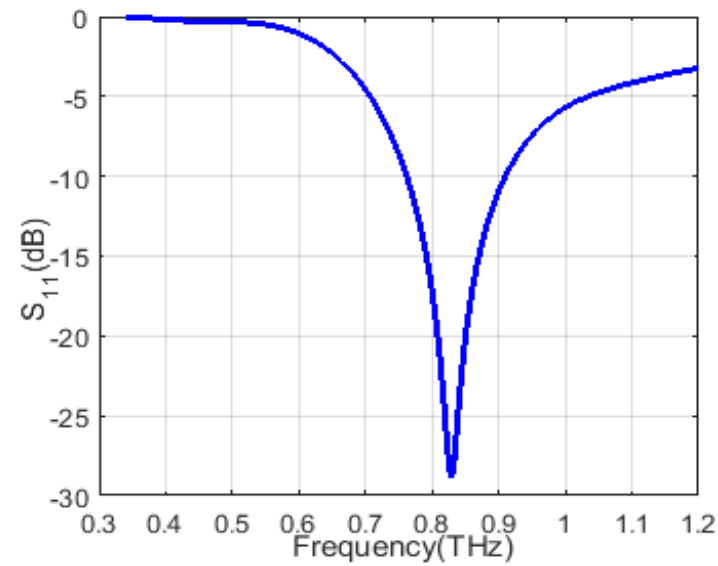

b.

Fig .8 a. The first proposed dipole antenna construction and b. the variation of its reflection coefficient versus frequency.

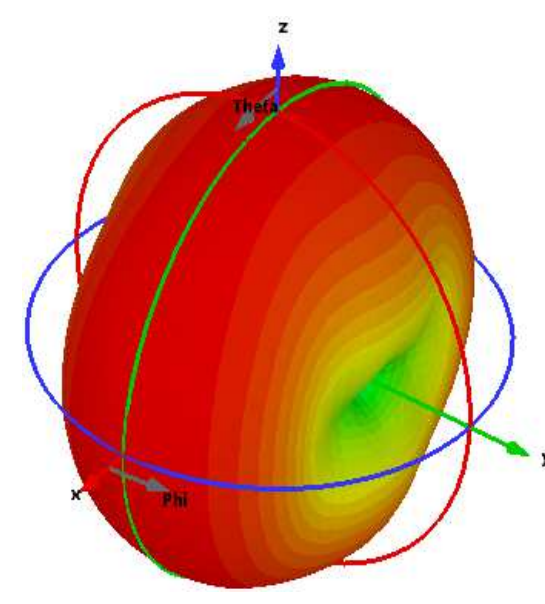

a.

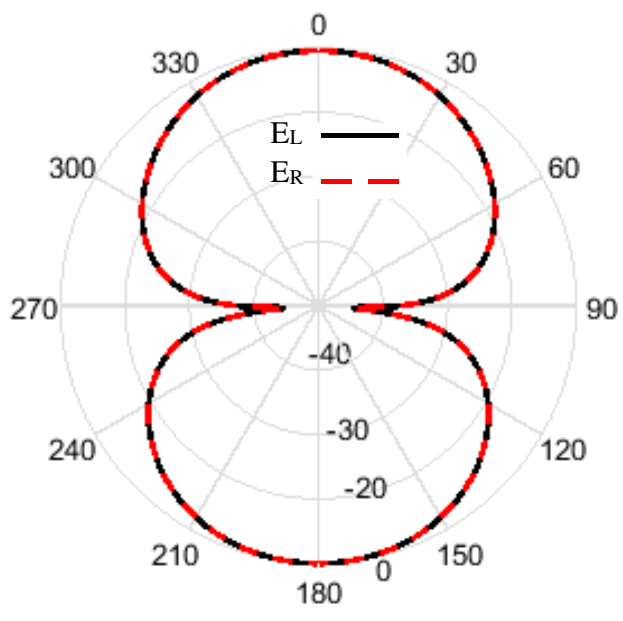

b.

Fig .9 a. The dipole antenna's radiation pattern in three dimensions and $b$. the two-dimensional components of the radiated electric field of the dipole antenna.

The second proposed dipole antenna (antenna B) that resonates at $0.5 \mathrm{THz}$ has the same structure of the first one but with scaled dimensions as shown in Fig. 10.a. This antenna operates over a $-10 \mathrm{~dB}$ bandwidth ranging from $0.46 \mathrm{THz}$ to $0.55 \mathrm{THz}(18 \% \mathrm{BW})$, as shown in Fig .10b. The proposed $0.5 \mathrm{THz}$ dipole antenna radiates an LP wave omnidirectionally with a maximum gain value of $2.69 \mathrm{dBi}$, as shown in Fig .11a. The 2D components of the radiated left $\left(\mathrm{E}_{\mathrm{L}}\right)$ and right $\left(\mathrm{E}_{\mathrm{R}}\right)$ hand electric field are equal at the operating frequency, as shown in Fig .11b. 


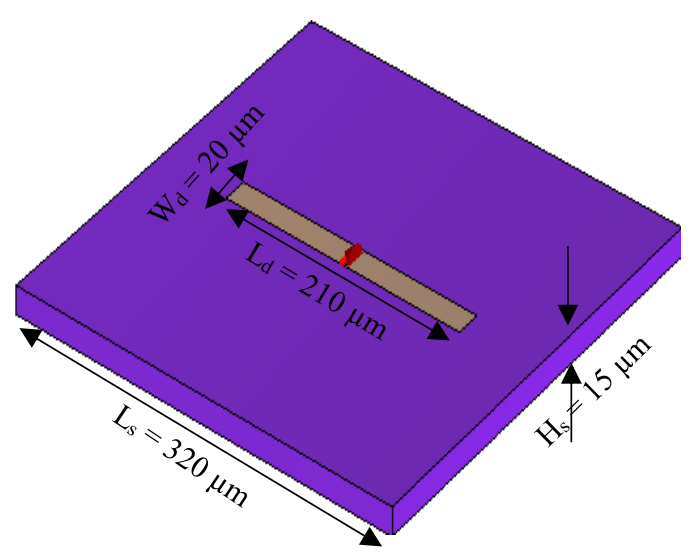

a.

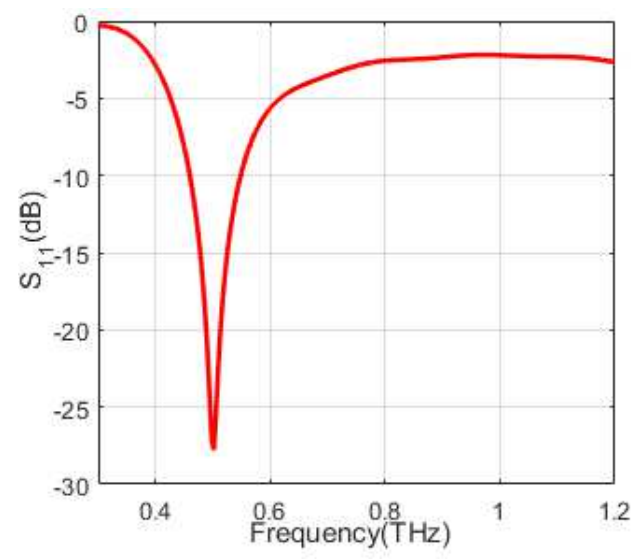

b.

Fig .10 a. The first proposed dipole antenna construction and b. the variation of its reflection coefficient versus frequency.

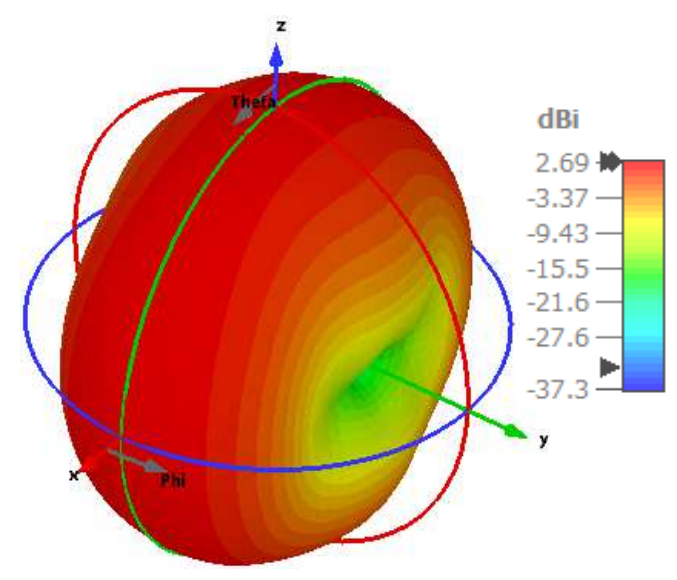

a.

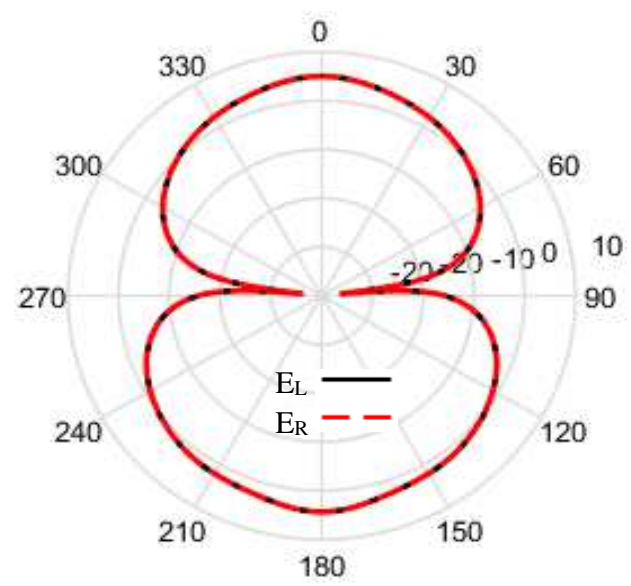

b.

Fig .11 a. The dipole antenna's radiation pattern in three dimensions and $b$. the two-dimensional components of the radiated electric field of the dipole antenna.

\section{B. The Proposed Dipole Antennas Over $\mathbf{N}$ x N Dual-Band FSS Unit-cell Element}

The proposed dual-band FSS unit-cell element when all switches turned OFF is arranged in $\mathrm{N} x \mathrm{~N}$ periodic surface and used as a reflector for the antenna (A), as shown in Fig .12 where $\mathrm{N}$ is the number of the FSS unit-cell elements. $\mathrm{N}$ value is varied from three; the value enables the FSS surface to cover the dipole antenna's surface area. Then the value of $\mathrm{N}$ is increased to detect the optimum value that produces the height gain.

The dipole antenna (A) is placed over the FSS surface at a distance (h). A parametric study for this height value is done. It was found that, as the number of the unit-cell elements increases, the matching values also increase, as shown in Fig.13. So, the FSS array of $7 \times 7$ achieved the best matching values were obtained for $h_{3}=0.5 \lambda_{\mathrm{o}}\left(\lambda_{\mathrm{o}}\right.$ is the operating wavelength). 


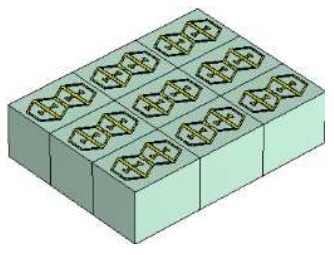

a.

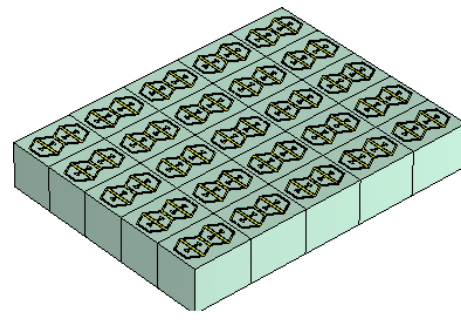

b.

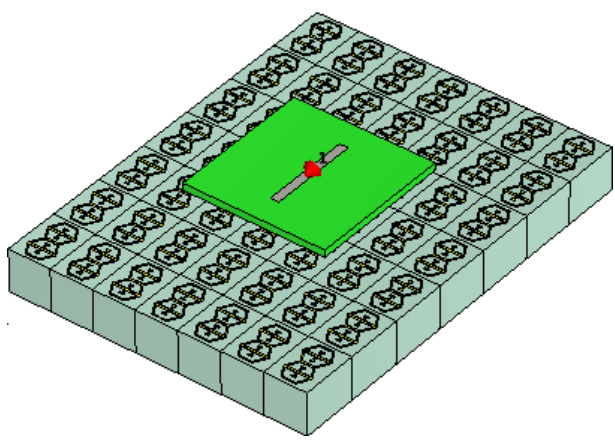

c.

Fig .12 The periodic structure of the dual-band FSS unit-cell elements as a reflector for the proposed dipole antenna (A) for a. $\mathrm{N}=3, \mathrm{~N}=5$, and $\mathrm{N}=7$.

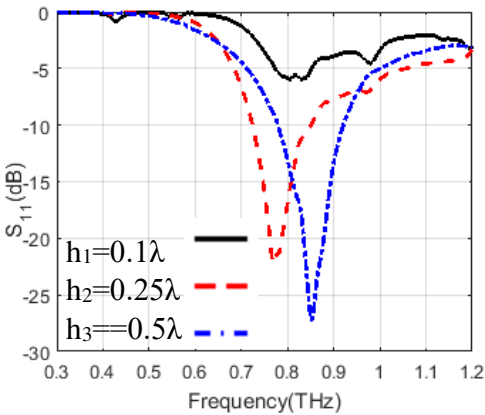

a.

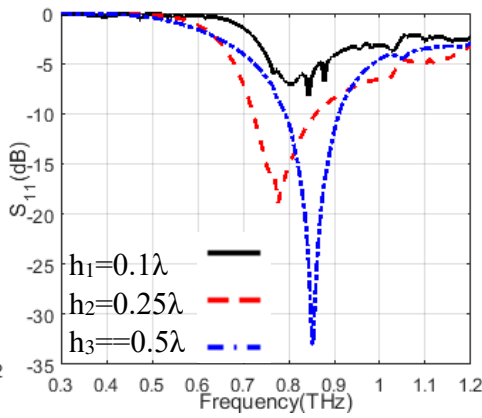

b.

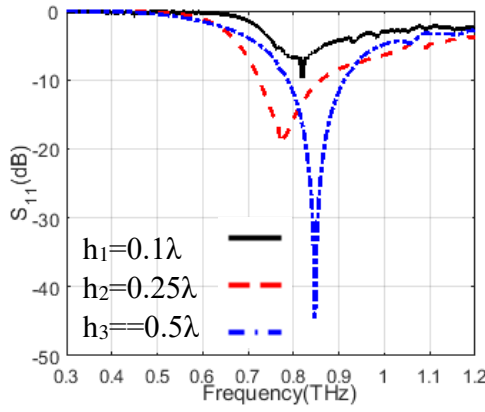

c.

Fig .13 The variations of the reflection coefficient versus frequency at different heights values for a. $\mathrm{N}=$ $3, \mathrm{~N}=5$, and $\mathrm{N}=7$.

For $\mathrm{N}=7$, when the proposed dipole antenna (A) is placed at a distance of $\mathrm{h}_{1}=0.1 \lambda_{\mathrm{o}}$, no matching is achieved, as shown in Fig .12c. This means the array did not behave as an FSS surface, and the radiation pattern of the dipole antenna did not reflect as in Fig. 13a. If this distance increased to $h_{2}=0.25 \lambda_{0}$, a wide frequency bandwidth from $0.71 \mathrm{THz}$ to $0.95 \mathrm{THz}(30 \% \mathrm{~B} . \mathrm{W})$ is obtained as in Fig .13c. Moreover, a single reflected beam with a maximum value of $8.48 \mathrm{dBi}$ is obtained at $0.83 \mathrm{THz}$, as shown in Fig .14b. However, if the antenna is placed at the height of $\mathrm{h}_{3}=0.5 \lambda_{\mathrm{o}}$, the reflected beam is diffracted into two directions, and the maximum gain values decreased to $6.32 \mathrm{dBi}$, as shown in Fig .14c.

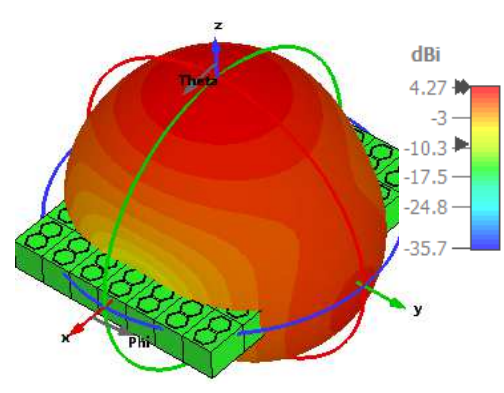

a.

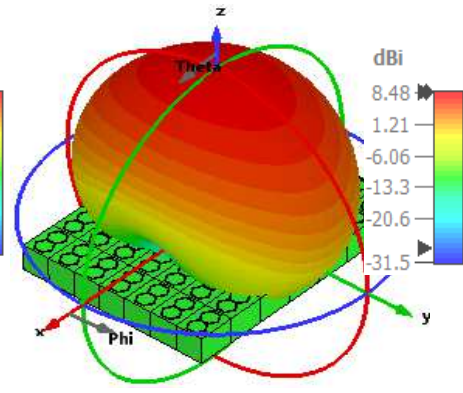

b.

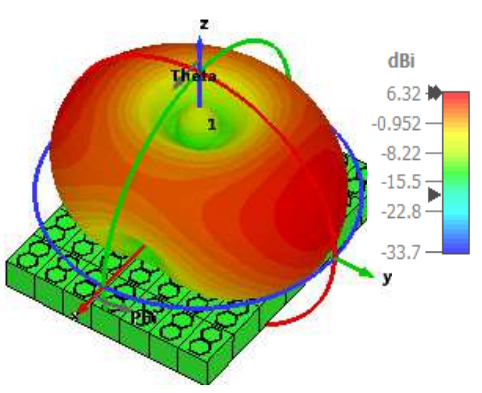

c.

Fig .14 The 3D radiation pattern of the proposed dipole antenna (A) over 7 x 7 FSS unit-cell elements' surface for a. $h_{1}=0.1 \lambda_{o}, b . h_{2}=0.25 \lambda_{0}$, and $h_{3}=0.5 \lambda_{\circ}$.

The optimum configuration results are obtained when the proposed dipole antenna (A) is placed at a distance of $0.25 \lambda_{\mathrm{o}}$ over $7 \times 7$ FSS surface with a surface area of $420 \mu \mathrm{m}$ x $555.45 \mu \mathrm{m}$. Moreover, plotting the 2D left and right components of the radiated electric field indicates that the FSS surface succeeds in 
converting the dipole antenna's linear polarized wave into circularly polarized at a frequency of $0.82 \mathrm{THz}$, as shown in Fig .15a. When the photoconductive switches are turned ON, the FSS unit-cell is no longer able to achieve polarization conversion where $E_{R}$ and $E_{L}$ have the same values, as shown in Fig .15b.

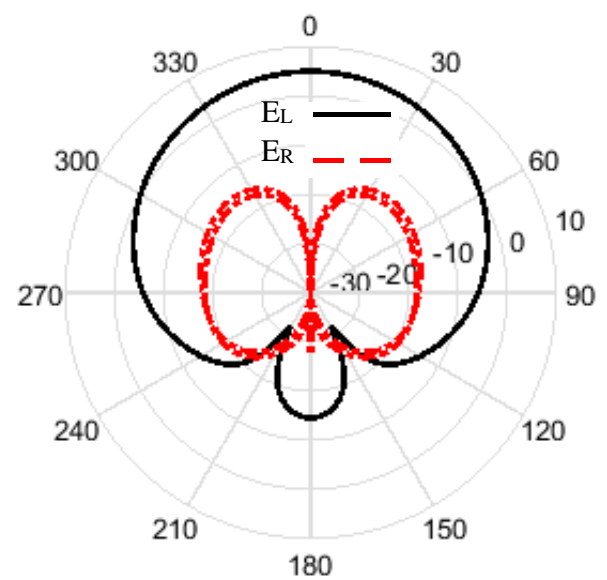

a.

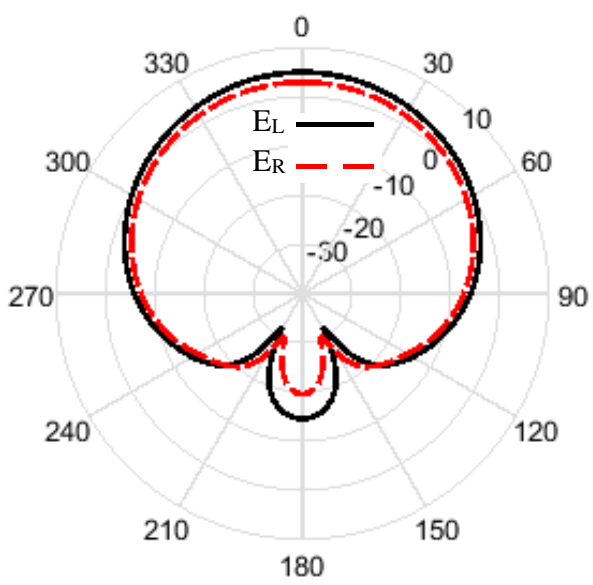

b.

Fig .15 The 2D components of the radiated electric field of the dipole antenna (A) over 7 x 7 FSS surface a. when all switches are turned OFF and $b$. when all switches are turned ON.

For the optimum configuration settings of the antenna over an FSS-based array, the proposed dipole antenna (A) is replaced by antenna (B) as an application for the FSS band ranging from $0.46 \mathrm{THz}$ to 0.56 THz. It was found that the 2D left and right components of the radiated electric field are equal, indicating that the FSS surface succeeds in converting the dipole antenna's linear polarized wave into circularly polarized at a frequency of $0.5 \mathrm{THz}$ as shown in Fig .16a. When the photoconductive switches of the FSS unit-cell elements are turned ON, the FSS unit-cell is no longer able to achieve polarization conversion where $E_{R}$ and $E_{L}$ have the same values, as shown in Fig .16b.

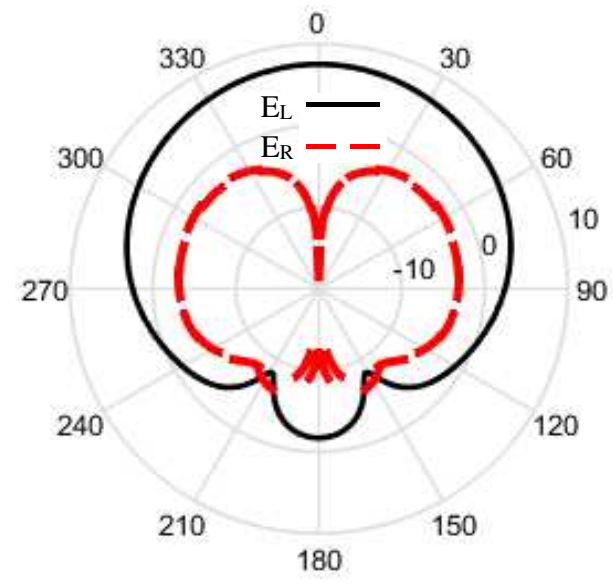

a.

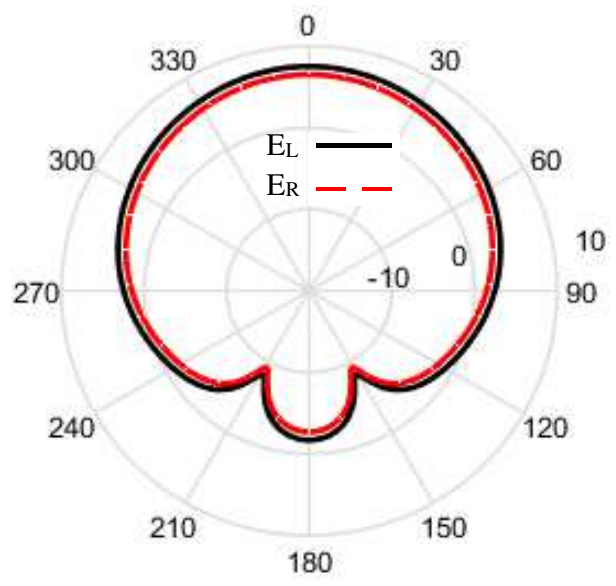

b.

Fig .16 The 2D components of the radiated electric field of the dipole antenna (B) over 7 x 7 FSS surface a. when all switches are turned OFF and b. when all switches are turned ON.

It was found that when the photoconductive switches of the unit-cell elements are turned OFF, the linear polarized waves of both antennas are converted into circularly polarized waves. The axial ratio of the two antennas is calculated and figured, confirming the ability of the proposed FSS-based surface to perform 
polarization conversion for two different antenna with two different operating frequencies, as shown in Fig. 17. Antenna (A) has a $3 \mathrm{~dB}$ axial ratio band ranging from $0.8 \mathrm{THz}$ to $0.98 \mathrm{THz}(19.5 \% 3 \mathrm{~dB}-\mathrm{AR} \mathrm{BW})$, and antenna (B) has a $3 \mathrm{~dB}$ axial ratio band ranging from $0.47 \mathrm{THz}$ to $0.61 \mathrm{THz}(28 \% 3 \mathrm{~dB}-\mathrm{AR} \mathrm{BW})$.

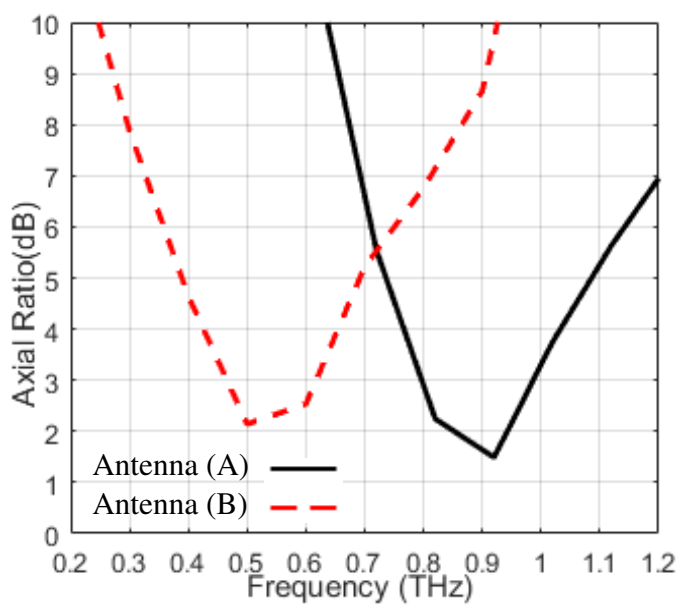

Fig .17 The variation of axial ratio versus frequency for antenna (A) and (B) over 7 x 7 FSS-based array.

\section{Conclusion}

A frequency reconfigurable single and dual-band terahertz polarization converter with a hexagonshaped polarizer utilizing FSS technology was studied and presented. The single band FSS unit-cell element exhibited frequency reconfigurability and polarization conversion in a wide band of frequencies from $0.59 \mathrm{THz}$ to $0.8 \mathrm{THz}$ (30\% 3-dB BW). The dual-band FSS unit-cell element exhibited frequency reconfigurability and polarization conversion over two frequency bands from $0.46 \mathrm{THz}$ to $0.56 \mathrm{THz}(20 \%$ 3-dB B.W) and from $0.82 \mathrm{THz}$ to $0.91 \mathrm{THz}(12 \% 3-\mathrm{dB}$ B.W). The dual-band FSS unit-cell element is arranged in a $7 \times 7$ array and used as a reflector for two different dipole antennas, enhancing their gain to approximately $8.4 \mathrm{dBi}$ and converting their polarization from LP to CP over two different frequency bands. The converter is adequate to operate at the terahertz bands and is sufficient for deployment.

\section{REFERENCES}

[1] G. Maral and M. Bousquet, Satellite Communications Systems: Systems, Techniques, and Technology, 5th Edition, Sussex, U.K.: Wiley, 2009.

[2] L. Martinez-Lopez, J. Rodriguez-Cuevas, J. I. Martinez-Lopez, and A. E. Martynyuk, "A multilayer circular polarizer based on bisected split-ring frequency selective surfaces," IEEE Antennas and Wireless Propagation Letters, vol. 13, pp. 153-156, 2014.

[3] M.-A. Joyal and J.-J. Laurin, "Design and analysis of a cascade circular polarization selective surface at K band," IEEE Transactions on Antennas and Propagation, vol. 62, no. 6, pp. 3043-3053, 2014.

[4] I.-Y. Tarn and S.-J. Chung, "A new advance in circular polarization selective surface - A three-layered CPSS without vertical conductive segments," IEEE Transactions on Antennas and Propagation, vol. 55, no. 2, pp. 460-467, 2007.

[5] H. So, A. Ando, K. M. T. Seki, and T. Sugiyama, "Directional multi-band antenna employing frequency selective surfaces," Electron. Lett., vol. 49, no. 4, pp. 243-245, 2013.

[6] S.-C. Chiu and S.-Y. Chen, "High gain circularly polarized resonant cavity antenna using FSS superstrate," in IEEE International Symposium on Antennas and Propagation (APSURSI), Spokane, WA, USA, 2011.

[7] Wang, "Controlling beam-width of an antenna using frequency selective surface superstrate," IEEE Antennas and Wireless Propagation Letters ( Volume: 13), pp. 213-216, 2014. 
[8] L. Li, Y. Li, Z. Wu, F. Huo, Y. Zhang, and C. Zhao, "Novel Polarization-Reconfigurable Converter Based on Multilayer Frequency-Selective Surfaces," in Proceedings of the IEEE | Vol. 103, No. 7, July $2015,2015$.

[9] A. Edalati and T. A. Denidni, "Frequency selective surfaces for beam-switching applications," IEEE Transactions on Antennas and Propagation ( Volume: 61, Issue: 1, Jan. 2013), pp. 195-200, 19 September 2012.

[10] S. Raman, P. Mohanan, N. Timmons and J. Morrison, "Microstrip-fed pattern- and polarizationreconfigurable compact truncated monopole antenna," IEEE Antennas and Wireless Propagation Letters (Volume: 12), pp. 710-713, 17 May 2013.

[11] E. Doumanis, G. Goussetis, R. Dickie and R. Cahill, "Electronically Reconfigurable Liquid Crystal Based mm-Wave Polarization Converter," IEEE Transactions on Antennas and Propagation 62(4), 2014.

[12] W. Pan, C. Huang, P. Chen, M. Pu, X. Ma, and X. Luo, "A beam steering horn antenna using active frequency selective surface," IEEE Transactions on Antennas and Propagation ( Volume: 61, Issue: 12), pp. 6218-6223, 2007 September 2013.

[13] J.-S. Row and J.-F. Tsai, "Frequency-reconfigurable microstrip patch antennas with circular polarization," IEEE Antennas and Wireless Propagation Letters (Volume: 13), pp. 1112-1115, 12 June 2014.

[14] T. Debogović, J. Bartolić, and J. Perruisseau-Carrier, "Dual-polarized partially reflective surface antenna with MEMS-based beam-width reconfiguration," IEEE Transactions on Antennas and Propagation ( Volume: 62, Issue: 1), pp. 228-236, January 2014.

[15] S. P. Singh, A. K. Jha, and M. J. Akhtar, "Design of Broadband Superstrate FSS for Terahertz Imaging and Testing Applications," in International Microwave and RF Conference (IMaRC), New Delhi, India, 2016.

[16] V. Petrov, A. Pyattaev, D. Maltchanov, and Y. Koucheryavy, "Terahertz band communications: Applications, research challenges, and standardization activities," in 8th International Congress on Ultra Modern Telecommunications and Control Systems and Workshops (ICUMT), Lisbon, Portugal, 2016.

[17] M. A. Sofi, K. Saurav, and S. K. Koul, "Reconfigurable Polarization Converter Printed on Single Substrate Layer Frequency Selective Surface," in IEEE MTT-S International Microwave and RF Conference (IMARC), Mumbai, India, 2019.

[18] S. Pendharker, R. K. Shevgaonkar and A. N. Chandorkar, "Optically Controlled FrequencyReconfigurable Microstrip Antenna With Low Photoconductivity," in IEEE Antennas and Wireless Propagation Letters, vol. 13, pp. 99-102, 2014.

[19] Sodré Junior, Arismar Cerqueira, et al. "Optically controlled reconfigurable antenna array based on Eshaped elements." International Journal of Antennas and Propagation 2014.

[20] N. Ojaroudi Parchin, H. Jahanbakhsh Basherlou, Y. I. A. Al-Yasir, A. M. Abdulkhaleq, and R. A. Abd-Alhameed, "Reconfigurable Antennas: Switching Techniques-A Survey," Electronics, vol. 9, no. 2. 2020.

[21] X. Xu, Y.-M. Wu, D.-H. Lv, G. Cheng, N. Zhao, B. Li, and X. Lv, "Analysis and Design of Terahertz Stopband Filter Based on the Frequency-Selective Surface," in International Applied Computational Electromagnetics Society Symposium - China (ACES), Beijing, China, 2018.

[22] W. Liu et al., "Realization of broadband cross-polarization conversion in transmission mode in the terahertz region using a single-layer metasurface," Opt. Lett., vol. 40, no. 13, pp. 3185-3188, 2015.

[23] Y. Z. Cheng et al., "Ultrabroadband reflective polarization convertor for terahertz waves," Appl. Phys. Lett., vol. 105, no. 18, p. 181111, 2014. 


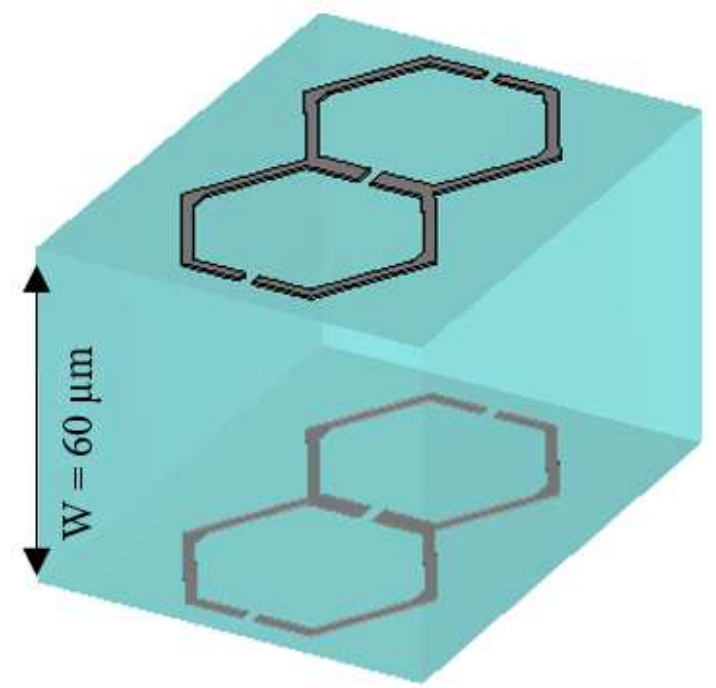

a.

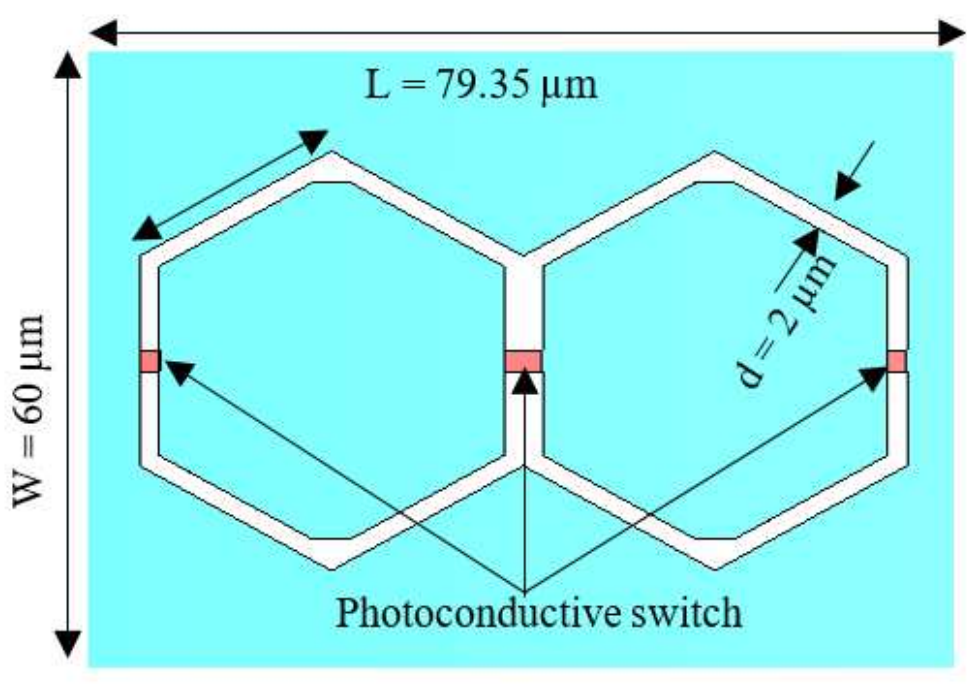

b.

\section{Figure 1}

a. The 3D view and $b$. the top view of the proposed FSS unit cell element's configuration.

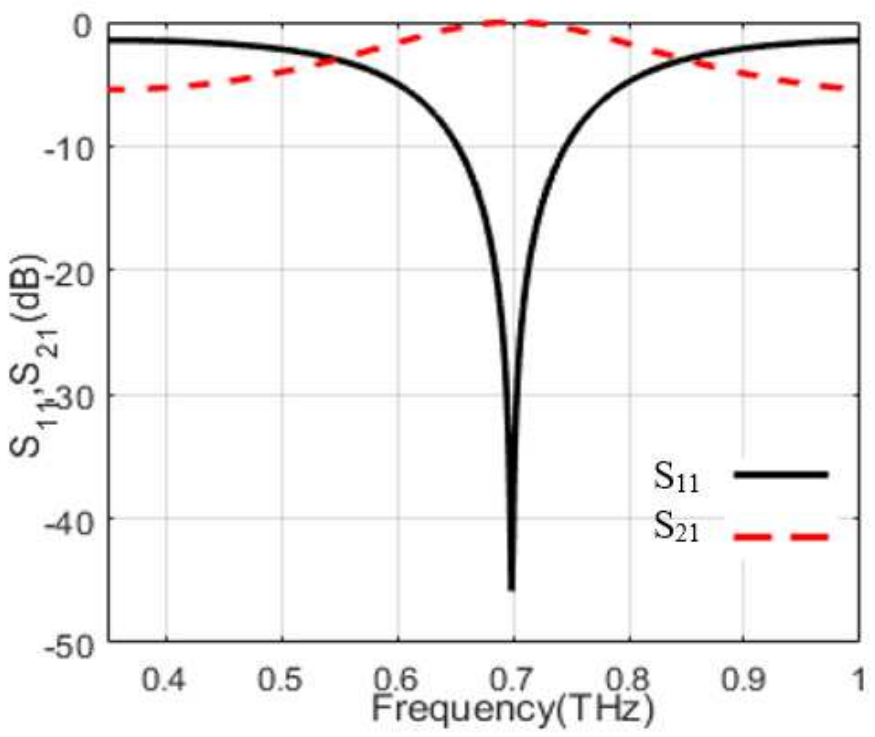

a.

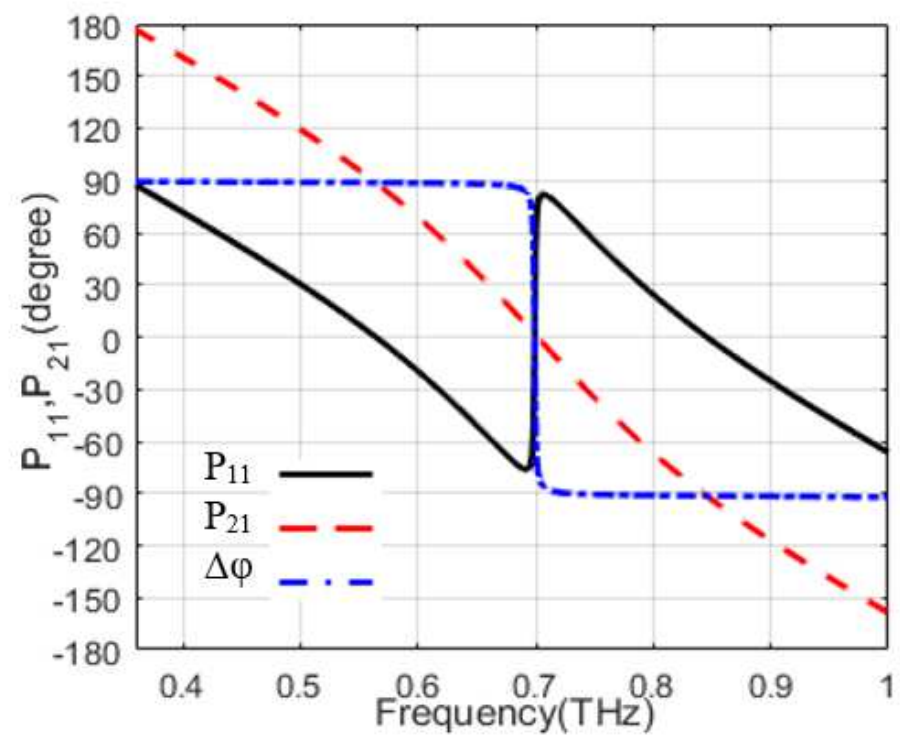

b.

Figure 2

The variation of $a$. the magnitude and $b$. the phase of the reflection and transmission coefficients of the proposed FSS unit-cell element when the switches are turned ON. 


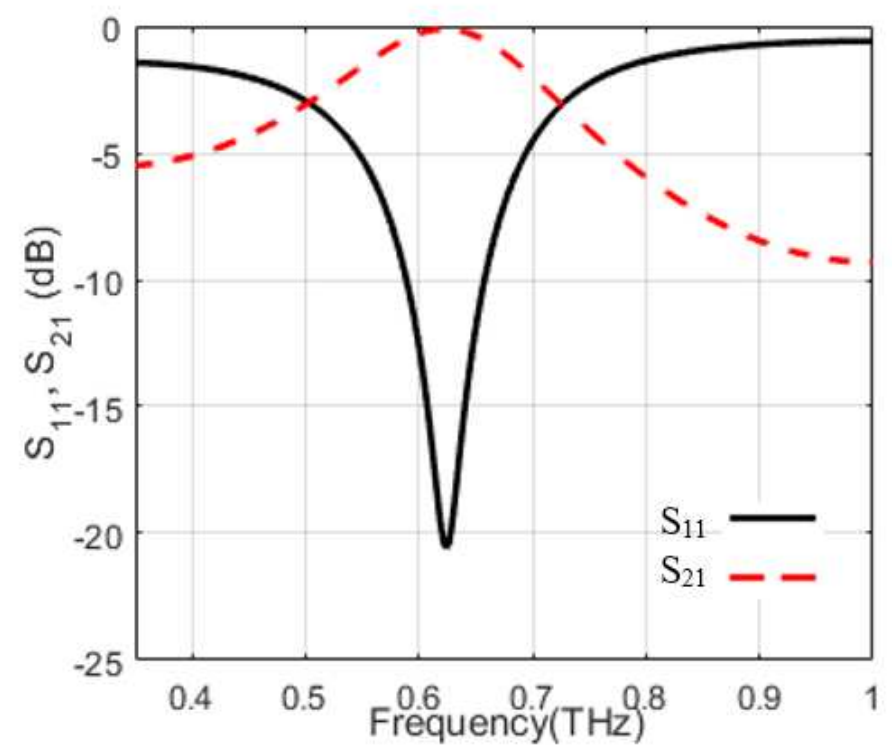

a.

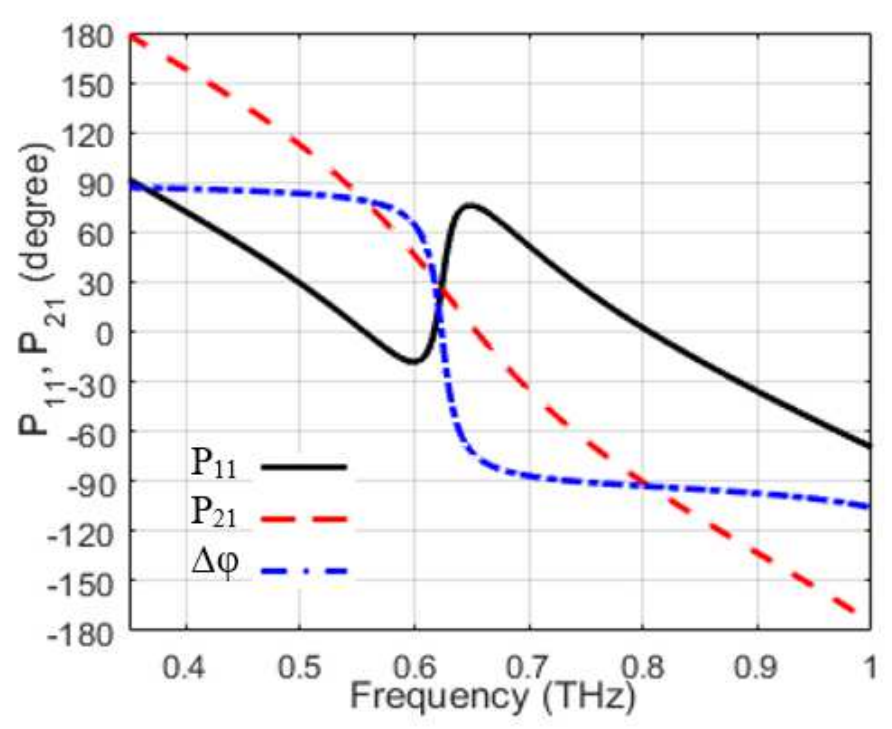

b.

\section{Figure 3}

The variation of $a$. the magnitude and $b$. the phase of the reflection and transmission coefficients of the proposed FSS unit-cell element when the switches are turned OFF.

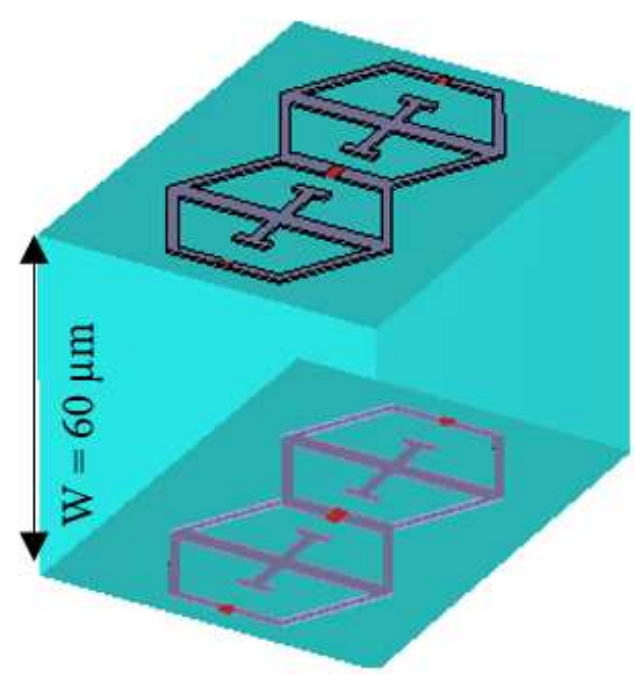

a.

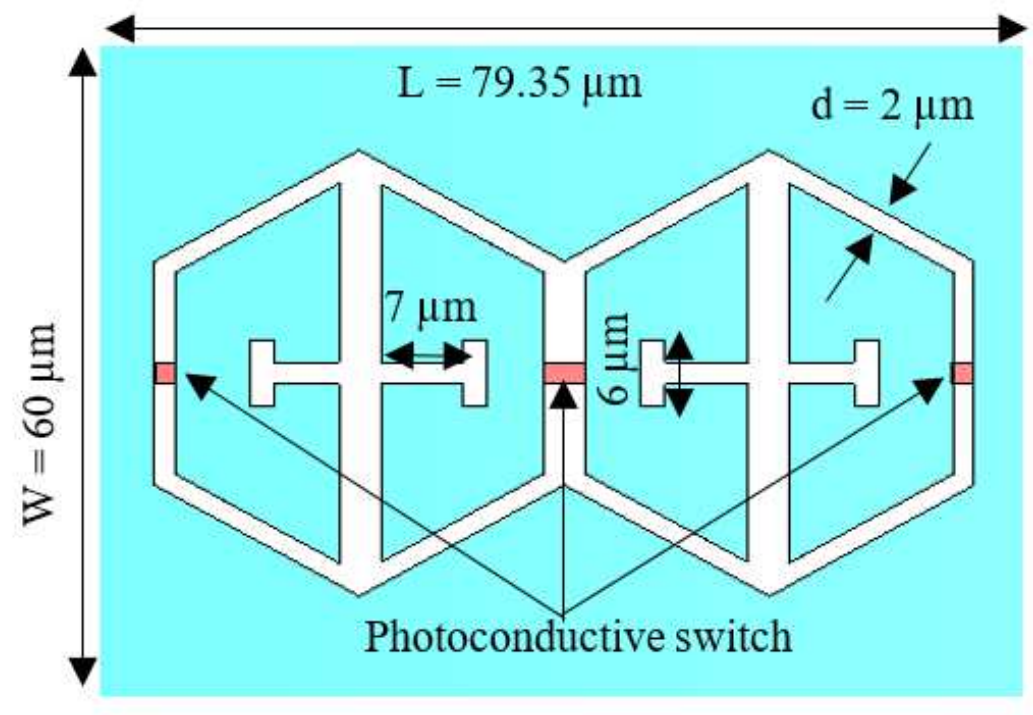

b.

Figure 4

a. The 3D view and $b$. the top view of the proposed dual-band FSS unit cell element's configuration. 


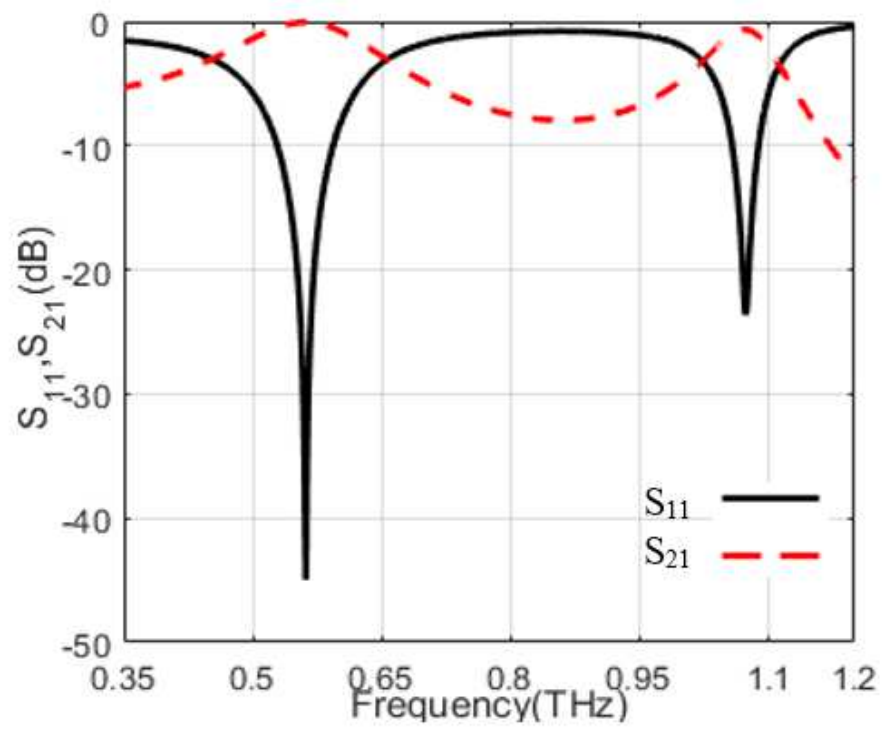

a.

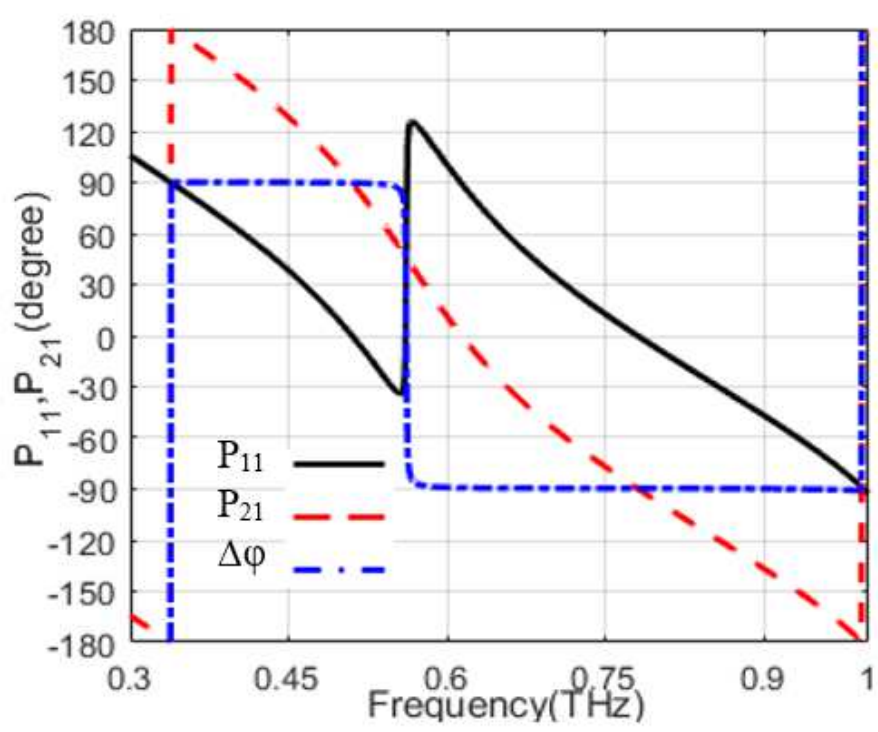

b.

Figure 5

The variation of $a$. the magnitude and $b$. the phase of the reflection and transmission coefficients of the proposed dual-band FSS unit-cell element when the switches are turned OFF.

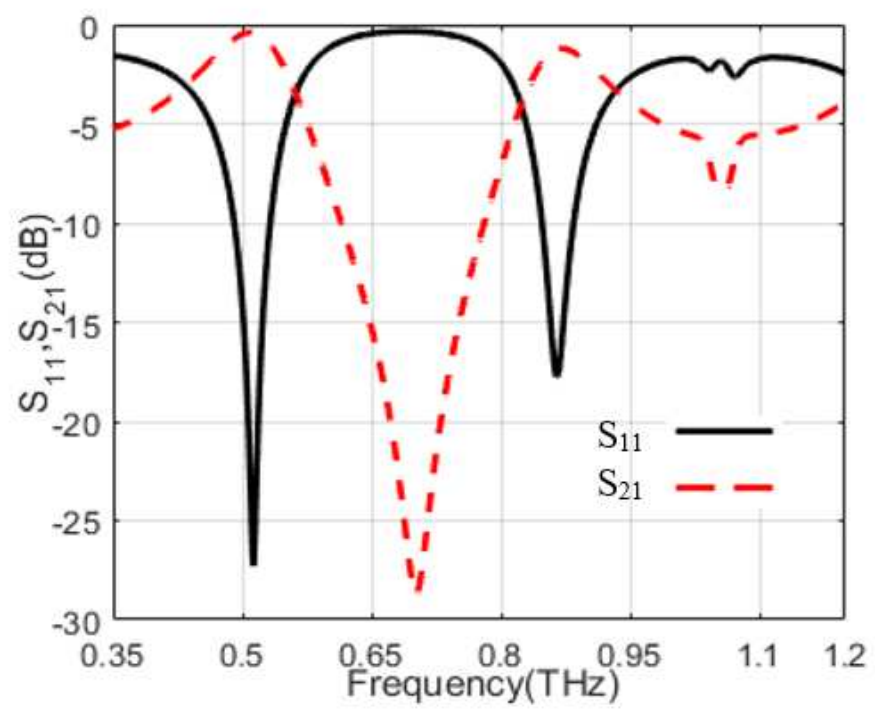

a.

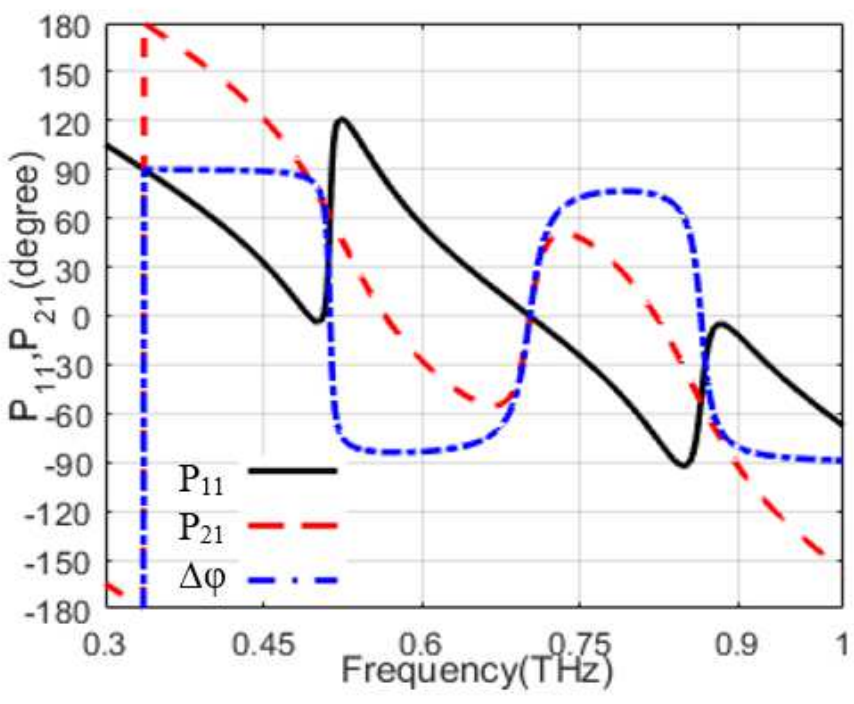

b.

Figure 6

The variation of $a$. the magnitude and $b$. the phase of the reflection and transmission coefficients of the proposed dual-band FSS unit-cell element when the switches are turned ON. 


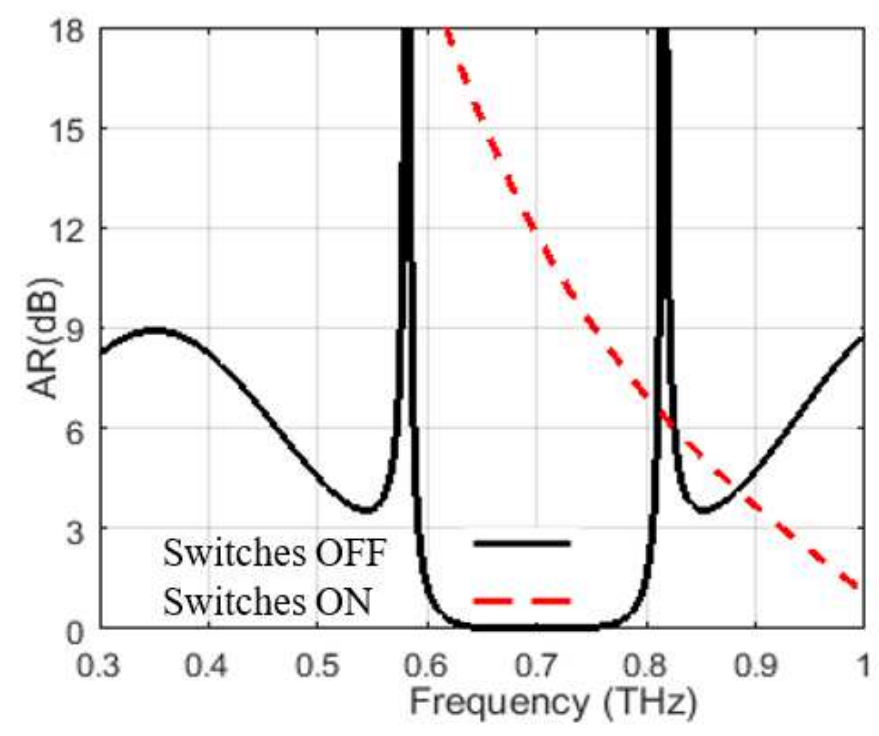

a.

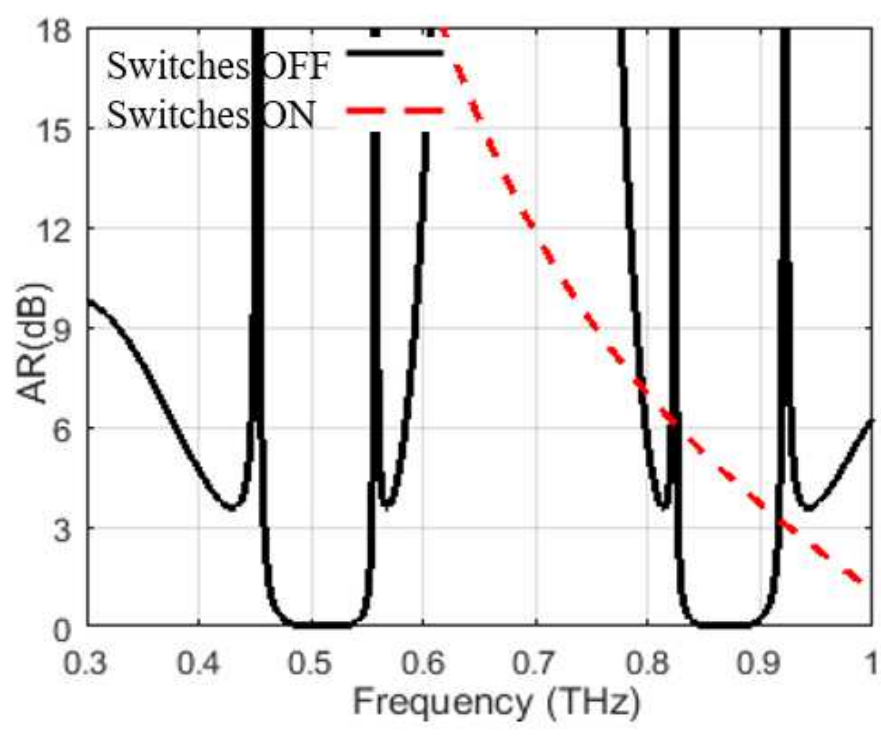

b.

Figure 7

The variation of axial ratio versus frequency for $a$. the single-band and $b$. the dual-band FSS unit-cell elements when the switches are turned OFF and ON.

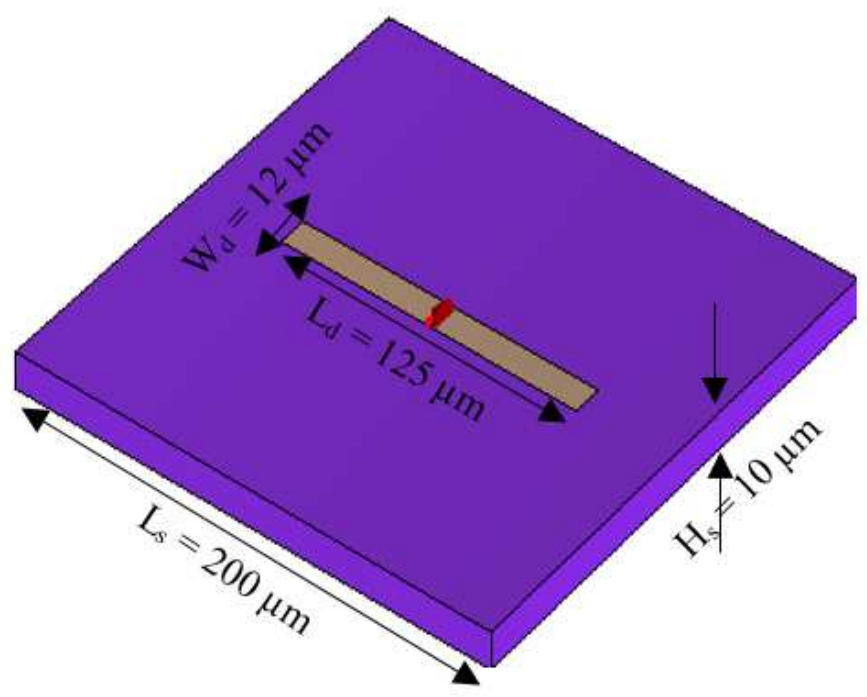

a.

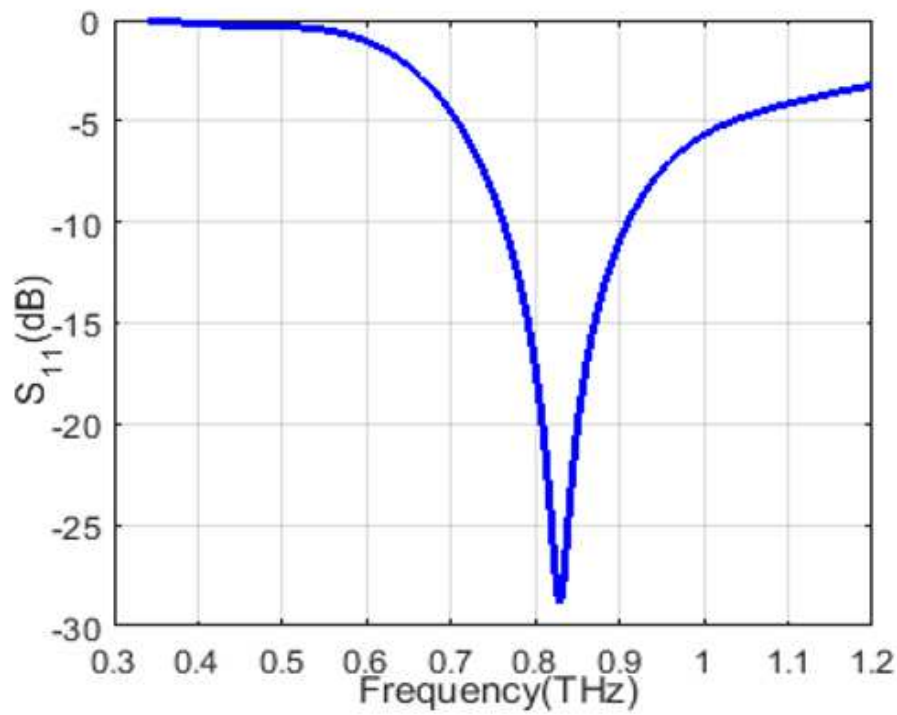

b.

Figure 8

a. The first proposed dipole antenna construction and $b$. the variation of its reflection coefficient versus frequency. 


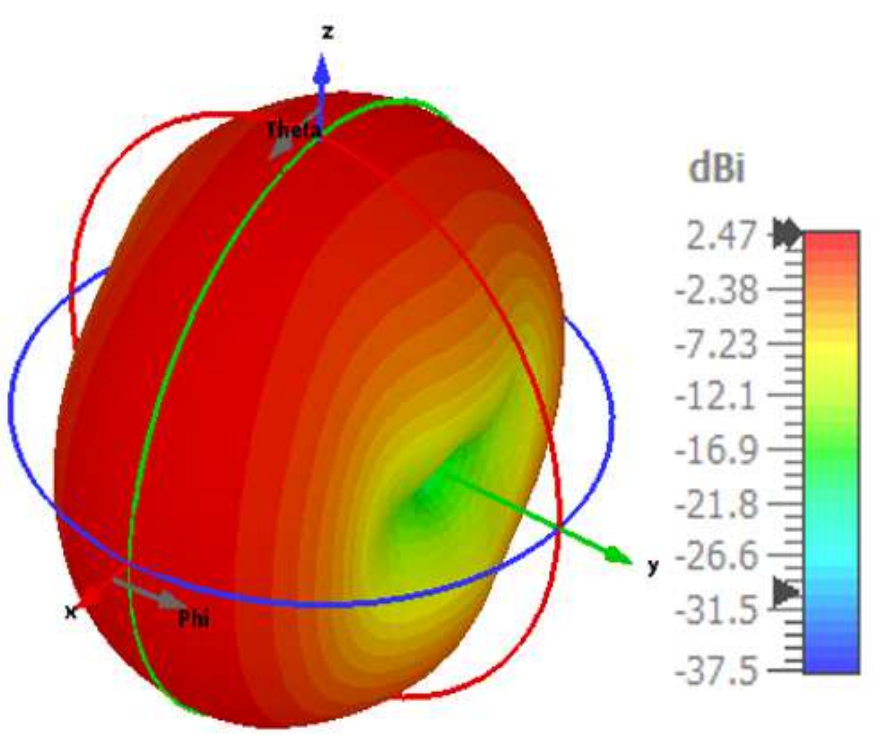

a.

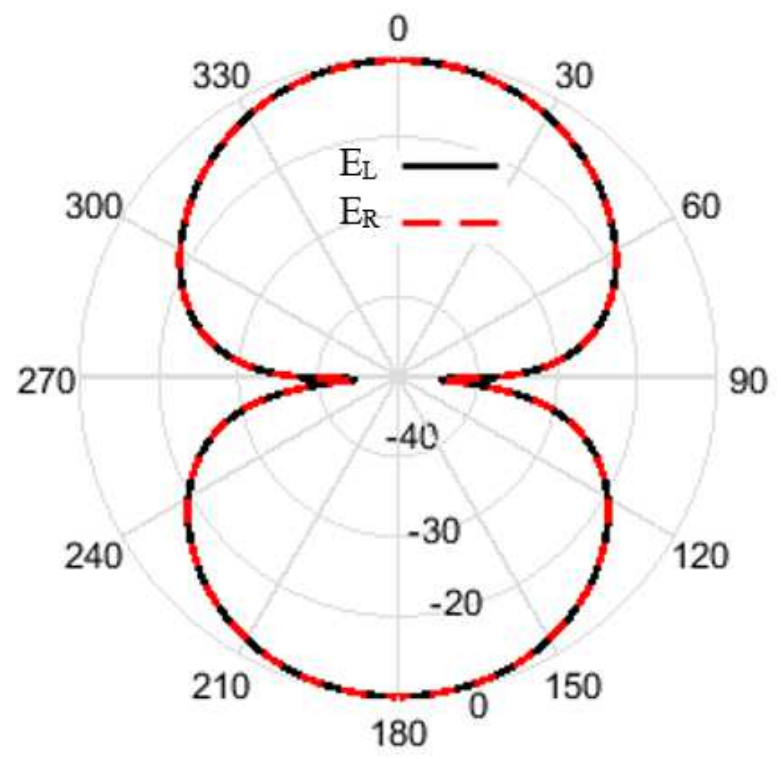

b.

\section{Figure 9}

a. The dipole antenna's radiation pattern in three dimensions and b. the two-dimensional components of the radiated electric field of the dipole antenna.

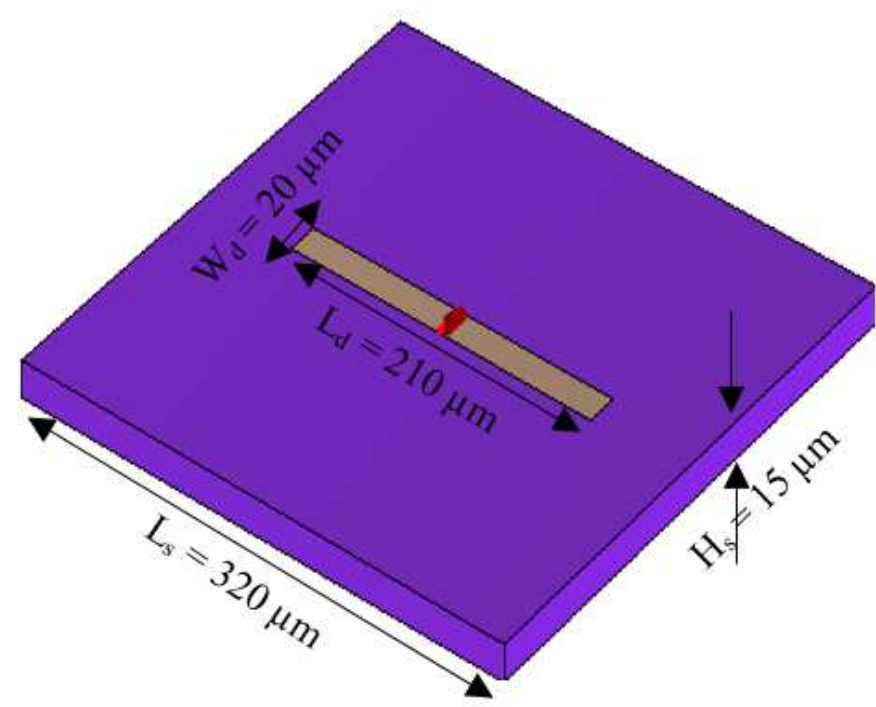

a.

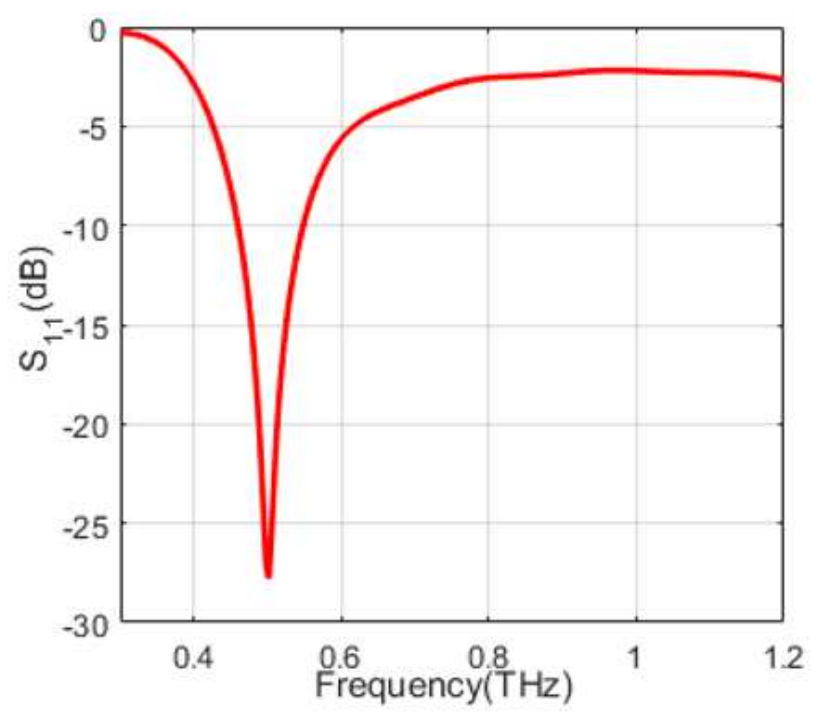

b.

Figure 10

a. The first proposed dipole antenna construction and $b$. the variation of its reflection coefficient versus frequency. 


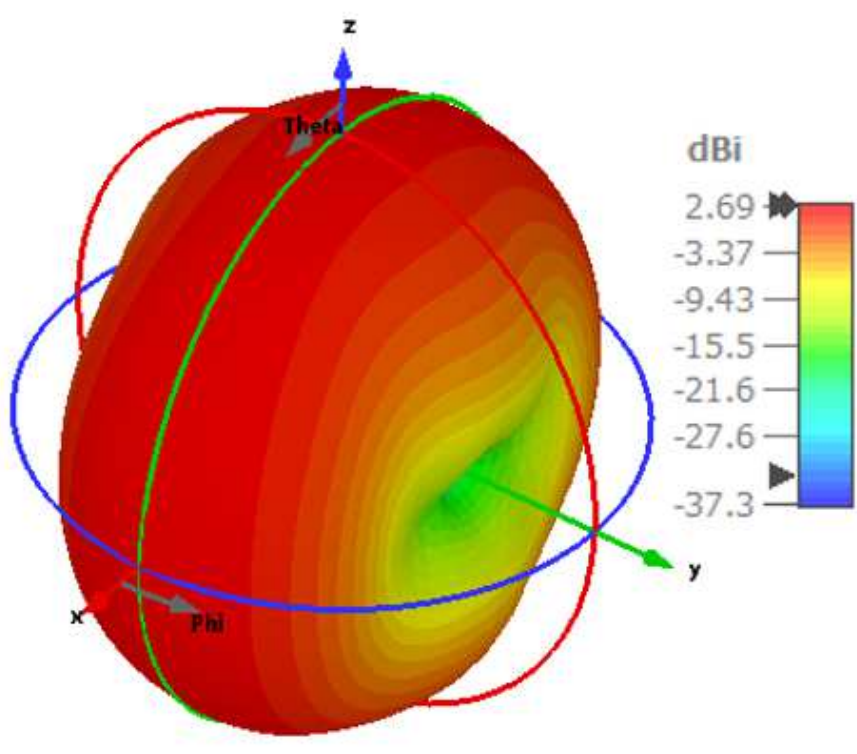

a.

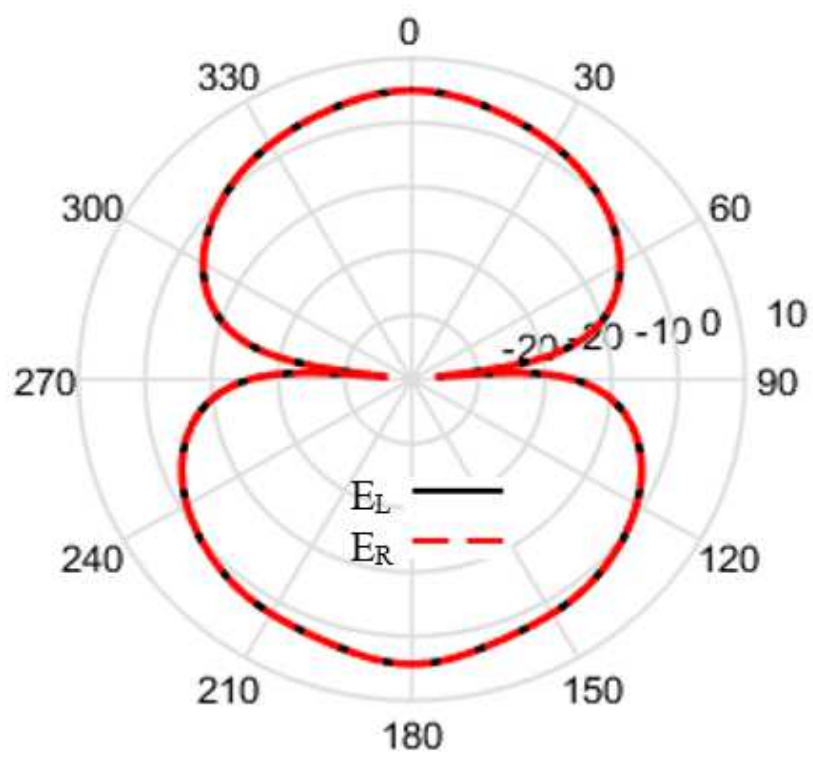

b.

\section{Figure 11}

a. The dipole antenna's radiation pattern in three dimensions and b. the two-dimensional components of the radiated electric field of the dipole antenna.

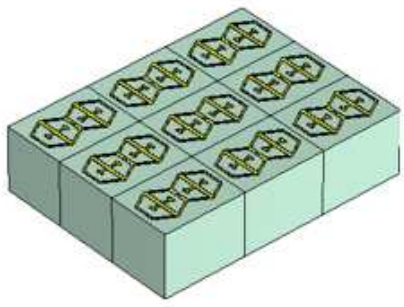

a.

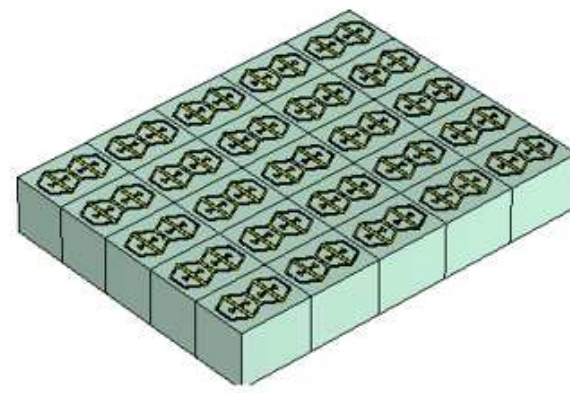

b.

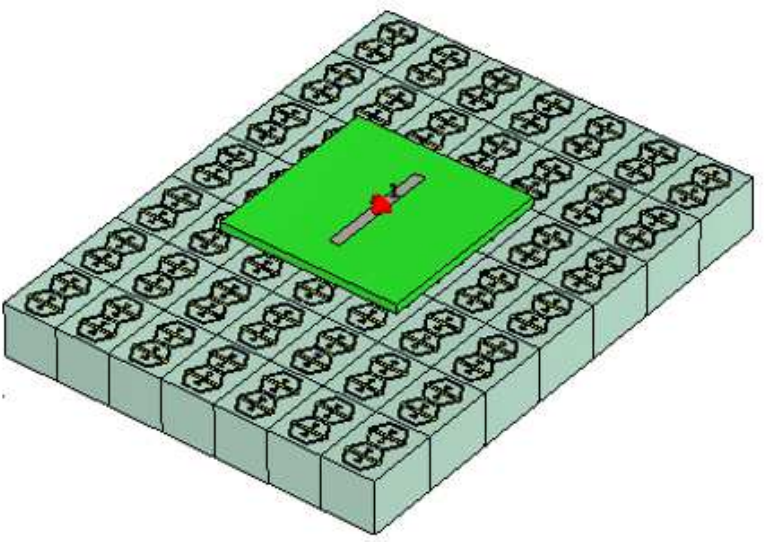

c.

Figure 12

The periodic structure of the dual-band FSS unit-cell elements as a reflector for the proposed dipole antenna (A) for a. $\mathrm{N}=3, \mathrm{~N}=5$, and $\mathrm{N}=7$. 


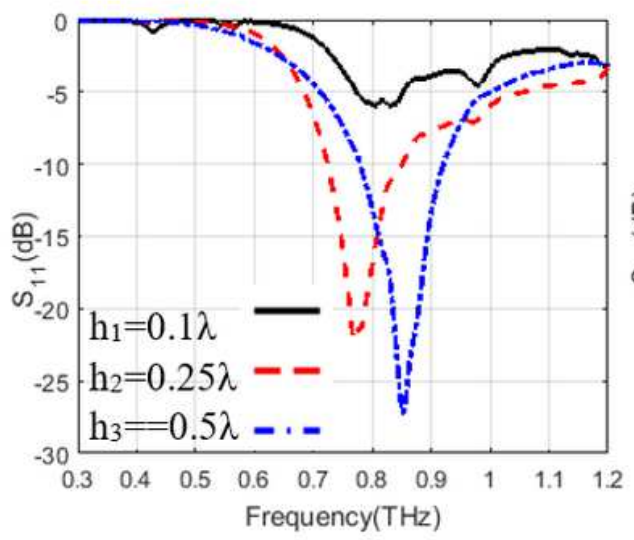

a.

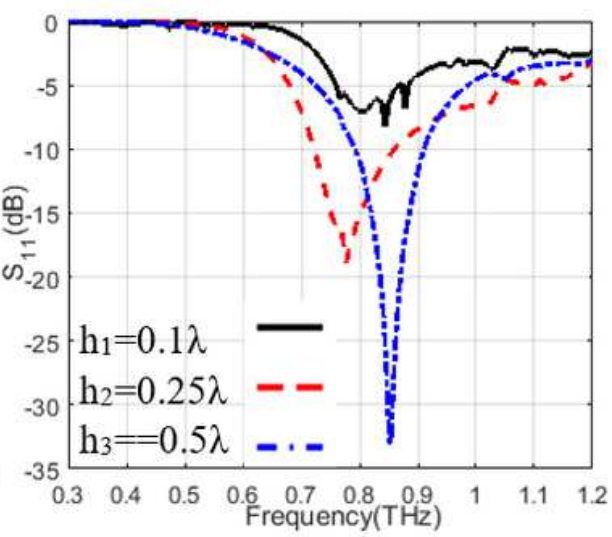

b.

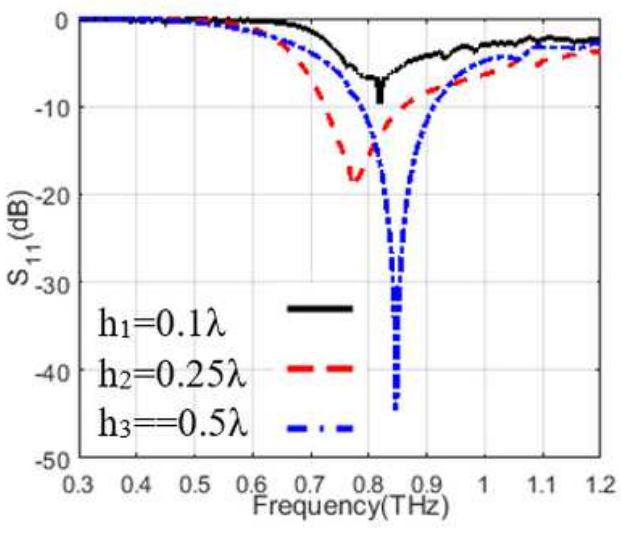

c.

\section{Figure 13}

The variations of the reflection coefficient versus frequency at different heights values for a. $N=3, N=5$, and $\mathrm{N}=7$.

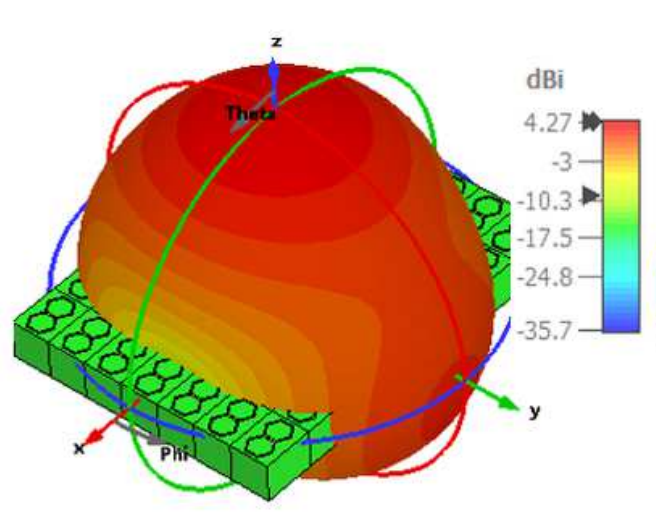

a.

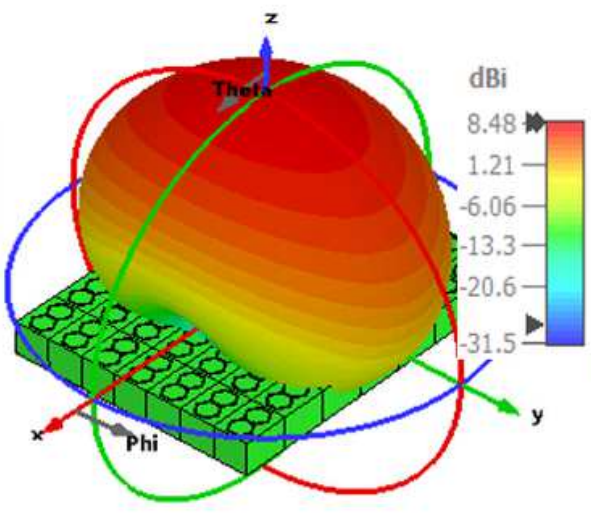

b.

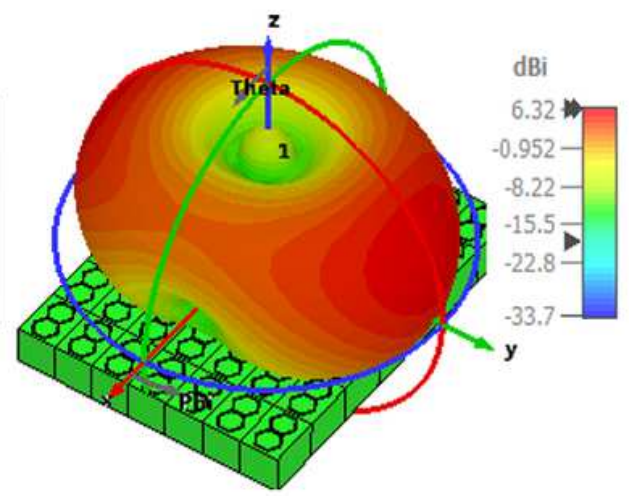

c.

\section{Figure 14}

The 3D radiation pattern of the proposed dipole antenna (A) over $7 \times 7$ FSS unit-cell elements' surface for a. $h 1=0.1 \lambda o, b . h 2=0.25 \lambda o$, and h3 = $0.5 \lambda$ o. 


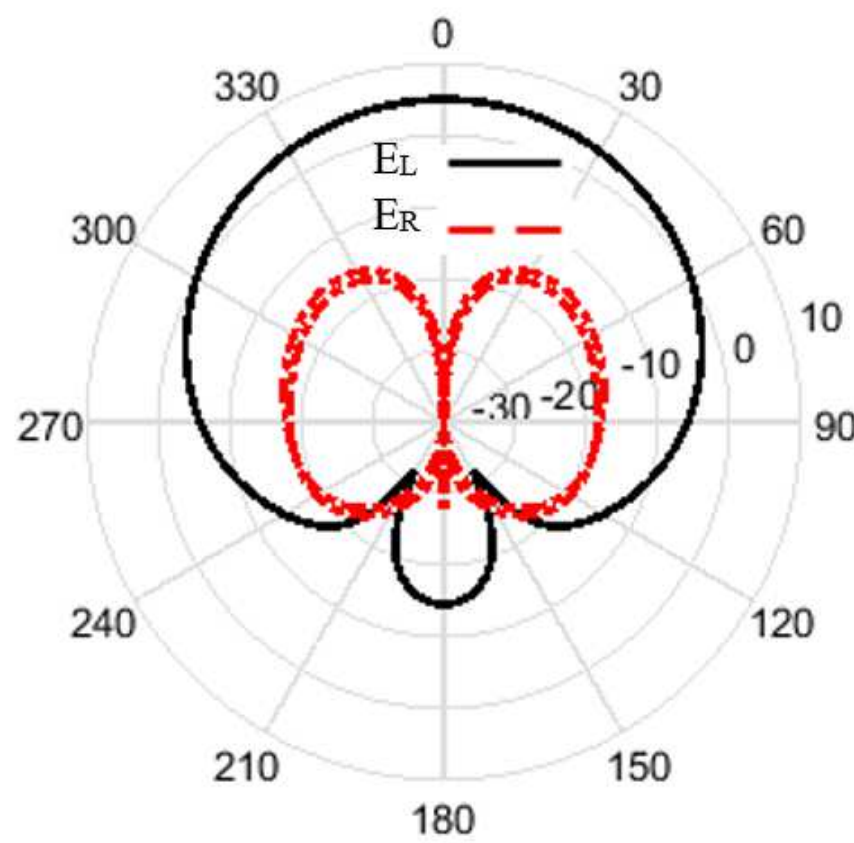

a.

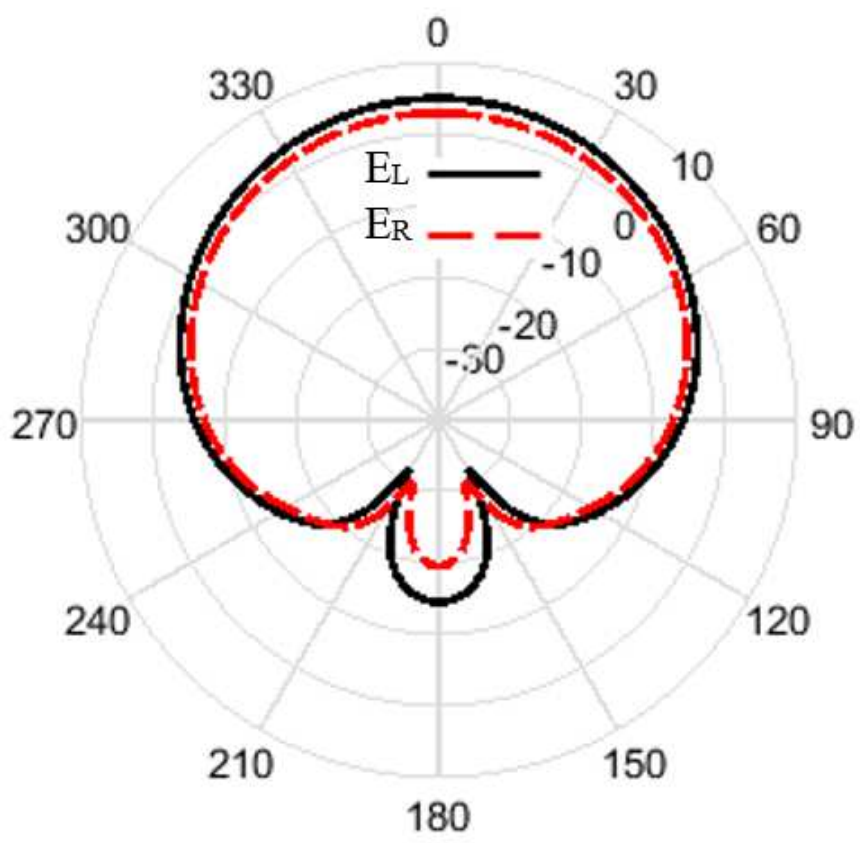

b.

\section{Figure 15}

The 2D components of the radiated electric field of the dipole antenna (A) over $7 \times 7$ FSS surface a. when all switches are turned OFF and $\mathrm{b}$. when all switches are turned ON.

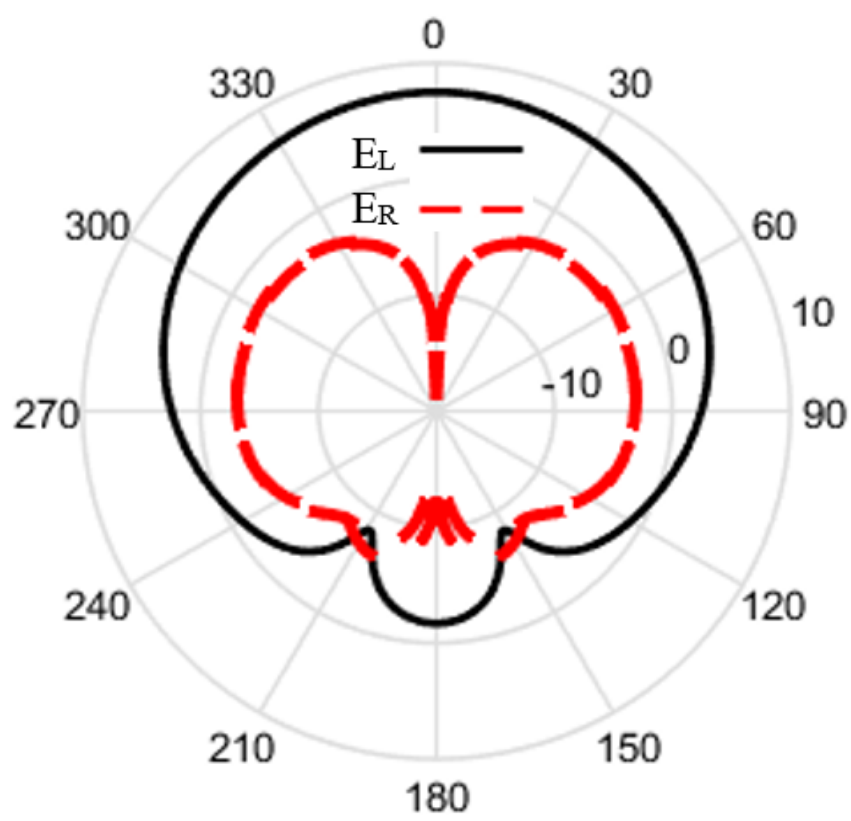

a.

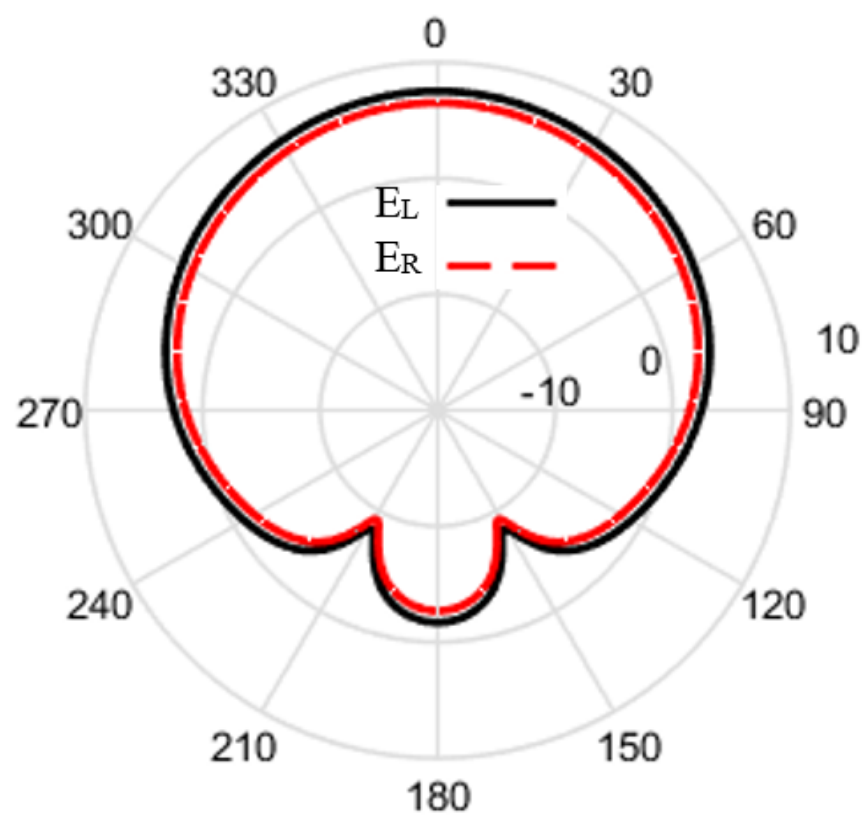

b.

\section{Figure 16}

The 2D components of the radiated electric field of the dipole antenna (B) over $7 \times 7$ FSS surface a. when all switches are turned OFF and $\mathrm{b}$. when all switches are turned ON. 


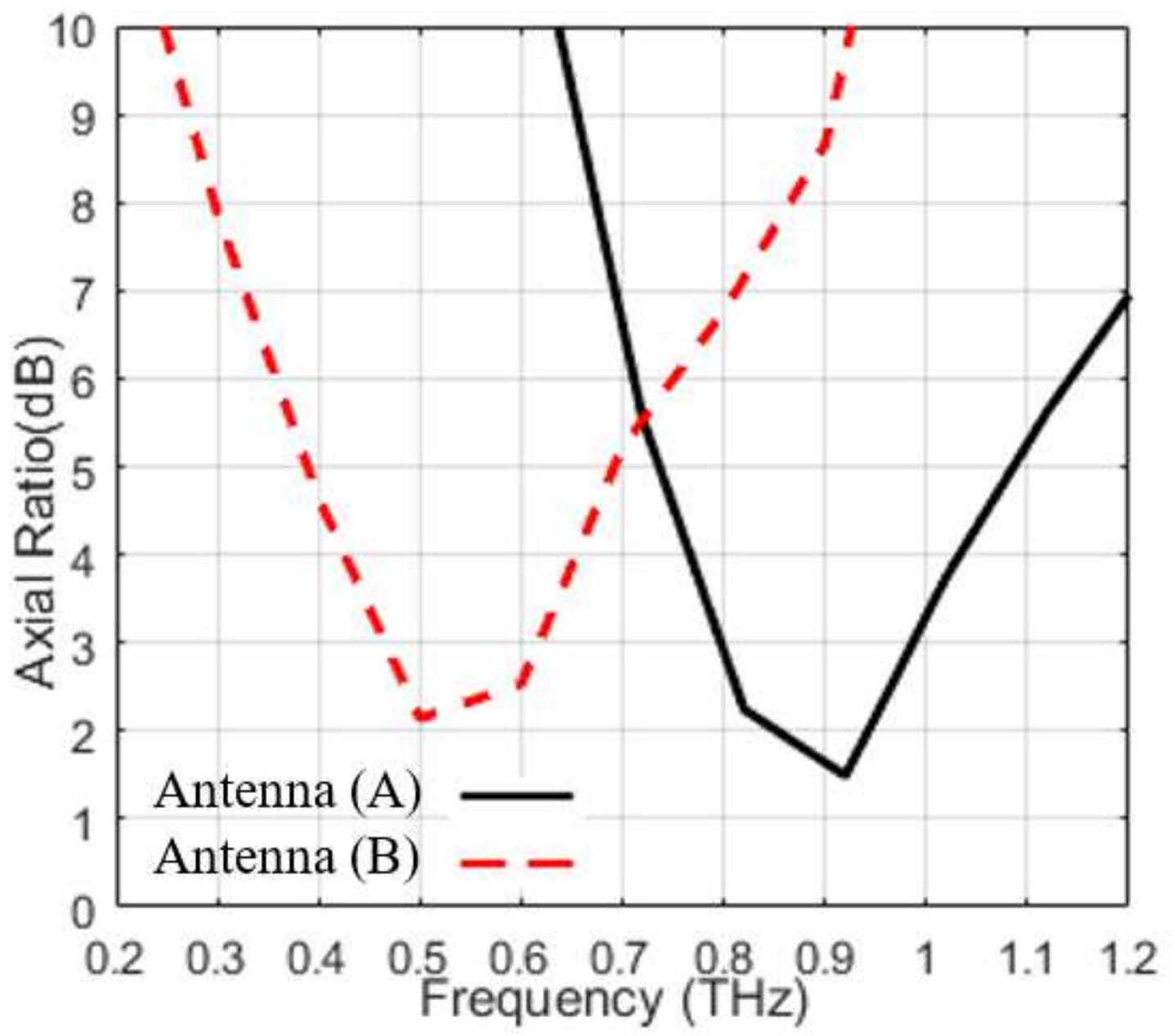

Figure 17

The variation of axial ratio versus frequency for antenna (A) and (B) over $7 \times 7$ FSS-based array. 